FÁBIO STREFEZZA

\title{
AVALIAÇÃO QUANTITATIVA E QUALITATIVA DA EXTRUSÃO APICAL EM TÉCNICAS DE OBTURAÇÃO TERMOPLASTIFICADA
}


Fábio Strefezza

\section{Avaliação quantitativa e qualitativa da extrusão apical em técnicas de obturação termoplastificada}

Tese apresentada à Faculdade de Odontologia da Universidade de São Paulo, para obter o título de Doutor pelo Programa de Pós-Graduação em Odontologia.

Área de Concentração: Endodontia

Orientador: Prof. Dr. Abilio Albuquerque Maranhão de Moura

São Paulo

2004 
Catalogação-na-Publicação

Serviço de Documentação Odontológica

Faculdade de Odontologia da Universidade de São Paulo

\section{Strefezza, Fábio}

Avaliação quantitativa e qualitativa da extrusão apical em técnicas de obturação termoplastificada / Fábio Strefezza; orientador Abilio Albuquerque Maranhão de Moura. -- São Paulo, 2004.

113p. : fig., tab., grafs., $30 \mathrm{~cm}$.

Tese (Doutorado - Programa de Pós-Graduação em Odontologia. Área de Concentração: Endodontia) -- Faculdade de Odontologia da Universidade de São Paulo.

1. Restauração dentária - Técnicas - Avaliação quantitativa 2. Materiais dentários - Técnicas termoplastificadas - Avaliação 3. Extrusão apical 4. Canal radicular - Restauração.

AUTORIZO A REPRODUÇÃO XEROGRÁFICA E DIVULGAÇÃO TOTAL OU PARCIAL DESTE TRABALHO, POR QUALQUER MEIO CONVENCIONAL OU ELETRÔNICO, PARA

FINS DE ESTUDO E PESQUISA, DESDE QUE CITADA A FONTE E COMUNICADA AO AUTOR A REFERÊNCIA DA CITAÇÃO.

São Paulo,

Assinatura:

E-mail: fabioste@usp.br 


\section{FOLHA DE APROVAÇÃO}

Strefezza F. Avaliação quantitativa e qualitativa da extrusão apical em técnicas de obturação termoplastificada [Tese de Doutorado]. São Paulo: Faculdade de Odontologia da USP; 2004.

São Paulo, /

\section{Banca Examinadora}

1) $\operatorname{Prof}(a) \cdot \operatorname{Dr}(a)$.

Titulação:

Julgamento:

Assinatura:

2) $\operatorname{Prof}(a) . \operatorname{Dr}(a)$.

Titulação:

Julgamento:

Assinatura:

3) $\operatorname{Prof}(a)$. Dr(a).

Titulação:

Julgamento:

Assinatura:

4) $\operatorname{Prof}(a) \cdot \operatorname{Dr}(a)$.

Titulação:

Julgamento:

Assinatura:

5) $\operatorname{Prof}(a) \cdot \operatorname{Dr}(a)$.

Titulação:

Julgamento:

Assinatura: 


\section{DEDICATÓRIAS}

A os meus pais, N orberto el Ida,

cujos exemplos de luta e esforços transmitidos com muito amor no decorrer da minha vida, estimularam-me a constante dedicação e perseverança para atingir os meus objetivos.

À minha esposa, amiga e companheira, E stela, a quem dedico este trabalho, por não medir esforços em me ajudar, estando ao meu lado em todos os momentos, com muito amor, apoio e dedicação, que são fatores primordiais para o fortalecimento da nossa união em todas as fases de nossas vidas.

Às minhas irmãs Cláudia e L iliana, e afilhados M aurício e D aniel, agradeço pela importância na constituição da união familiar. 
A o Prof. D r. A bilio A lbuquerque M aranhão de M oura,

um agradecimento especial pela orientação e confiança na realização desta tese, como também por todas as oportunidades na minha trajetória acadêmica, possibilitando o meu desenvolvimento profissional e conseqüentemente as minhas realizações pessoais. 


\section{AGRADECIMENTOS}

A o Prof. D r. J oão H umberto Antoniazzi pelos ensinamentos e experiências transmitidos no decorrer do Curso de Pós-Graduação.

A o Prof. D r. Harry Davidow icz pelo brilhantismo de suas idéias, amizade contínua, auxílio na elaboração desta pesquisa e em todos os momentos que precisei.

Às Profs. D ras. M iriam Porcel dos Santos Antonio e L ení Hamaoka pelo constante incentivo e amizade de sempre...

A Profa. Camilla de F reitas Carvalho pela amizade compartilhada em todas as fases deste Curso de Doutorado.

A os P rofs A bilio, H arry, M iriam, L ení, Camilla, Celina e Sergio, da Disciplina de Endodontia da Universidade Paulista, agradeço pela união e colaboração na fase qualitativa desta tese. 
Ao D r. Saul Antunes $N$ eto, Dr. Rodrigo Reis e M ariângela Ranchan pela credibilidade neste projeto e fornecimento dos instrumentos e materiais de obturação da marca Maillefer - Dentsply - Tulsa Dental Products.

A os Engenheiros Gideon Lopes F erreira e Tarsis E duardo Gonzalez L opes F erreira do Laboratório de Metrologia Volumétrica - FGG, pelo desenvolvimento tecnológico do sistema de mensuração.

Ao Prof. $M$ arco Aurélio $H$ iendlmeyer $F$ urtado pela disponibilidade na utilização do sistema Obtura II.

À D ra. Virgínia J ustamante De Sordi por sua dedicação e atenção na realização da revisão gramatical.

A os funcionários do Serviço de D ocumentação O dontológica da $F$ aculdade de Odontologia da U niversidade de São Paulo, em especial à A guida F eliziani pela colaboração no levantamento, normalização das citações e referências bibliográficas. 
Strefezza F. Avaliação quantitativa e qualitativa da extrusão apical em técnicas de obturação termoplastificada [Tese de Doutorado]. São Paulo: Faculdade de Odontologia da USP; 2004.

\section{RESUMO}

Atualmente, as técnicas de obturação com guta-percha termoplastificada têm mostrado eficiência na adaptação dos materiais obturadores às paredes do sistema de canais radiculares, promovendo um selamento tridimensional. Porém, com a utilização destas técnicas, há dificuldade no controle longitudinal durante a obturação, que poderia acarretar em extrusão do material obturador em direção aos tecidos perirradiculares, influenciando na reparação pós tratamento endodôntico. Assim, o propósito deste estudo foi avaliar in vitro a extrusão apical de quatro técnicas de obturação termoplastificada, Thermafil, Obtura II, Ultrafil 3D e Fusionada, através de uma nova metodologia de mensuração de volume do material obturador extruído, relacionando com a freqüência da extrusão visual de guta-percha e/ou cimento e a qualidade radiográfica final da obturação. Os resultados demonstraram que a metodologia do sistema de mensuração foi efetiva para quantificar o volume de material obturador extruído, constatando extrusão em todas as técnicas termoplastificadas empregadas neste estudo, porém, quantitativamente, os grupos experimentais não apresentaram diferenças estatisticamente significantes entre as médias de volumes. $\mathrm{Na}$ avaliação radiográfica da qualidade final das obturações termoplastificadas, há evidências de que a técnica Obtura II produziu obturações endodônticas com qualidades estatisticamente inferiores às demais técnicas. De modo geral, podemos considerar que as técnicas Thermafil, Ultrafil 3D e Fusionada apresentaram resultados semelhantes em relação ao volume do material obturador extruído e qualidade radiográfica final da obturação, enquanto que as técnicas Thermafil e Fusionada exibiram resultados mais favoráveis em relação à freqüência da extrusão visual de guta-percha e/ou cimento.

Palavras-Chave: Obturação do canal radicular - Guta-percha termoplastificada Extrusão apical . 
Strefezza F. Quantitative and qualitative evaluation of the apical extrusion in techniques of thermoplasticized obturation [Tese de Doutorado]. São Paulo:

Faculdade de Odontologia da USP; 2004.

\section{ABSTRACT}

In the present, the obturation techniques with termoplasticized gutta-percha have been proving efficiency in adaptation of the filling material to the walls of the root canal system, promoting a three-dimensional sealing. Even so, with the use of these techniques, there is difficulty in the longitudinal control during the obturation, that could cause the extrusion of the filling material in direction to the perirradicular tissues, influencing the healing after endodontic treatment. Thus, the purpose of this study was to evaluate in vitro the apical extrusion of four thermoplasticized obturation techniques, Thermafil, Obtura II, Ultrafil 3D and Fused, with a new methodology of volume's measurement of the extruded filling material, relating with the frequency of the visual extrusion of gutta-percha and/or sealer and the final radiographic's quality of obturation. The results demonstrated that the methodology of the measurement system was effective to quantify the volume of the extruded filling material, verifying extrusion in all the thermoplasticized techniques studied, even so, quantitatively, the experimental groups didn't present statistically significant differences among the averages of volumes. In the radiographic evaluation of the final quality of thermoplasticized obturation, there are evidences that Obtura II technique produced endodontic obturation with qualities statistically inferior of the other techniques. In general, we can consider that Thermafil, Ultrafil 3D and Fused techniques presented similar results in relation to the volume of the extruded filling material and the final radiographic's quality of obturation, while Thermafil and Fused techniques exhibited more favorable results in relation to frequency of visual extrusion of gutta-percha and/or sealer.

Key-words: Root canal obturation - Thermoplasticized gutta-percha - Apical extrusion. 


\section{LISTA DE ILUSTRAÇÕES}

Figura 4.2.1 - Sistema de mensuração (vista lateral) .50

Figura 4.2.2 - Sistema de mensuração (vista frontal) .50

Figura 4.2.3 - Vasos comunicantes .50

Figura 4.2.4. - Escala graduada. .50

Figura 4.2.5 - Dente posicionado no sistema de mensuração de volume 51

Figura 4.2.6 - Forno Thermaprep Plus . .53

Figura 4.2.7 - Aquecedor Obtura II 53

Figura 4.2.8 - Aquecedor Hygenic .54

Figura 4.2.9 -Técnica Fusionada .54

Figura 5.1 - Médias de volume de material obturador extruído dos grupos experimentais, expressos em $\mu \mathrm{l}$...

Figura 5.2 - Thermafil (G1) - espécime № 3 69

Figura 5.3 - Thermafil (G1) - espécime o 7 69

Figura 5.4 - Obtura II (G2) - espécime ํo 5 69 
Figura 5.5 - Obtura II (G2) - espécime № 13

Figura 5.6 - Ultrafil 3D (G3) - espécime no 4 69

Figura 5.7 - Ultrafil 3D (G3) - espécime oํ 14 69

Figura 5.8 - Fusionada (G4) - espécime № 7 . .70

Figura 5.9 - Fusionada (G4) - espécime № 2 .70

Figura 5.10 - Controle Positivo (GCP) - espécime no 1 . .70

Figura 5.11 - Controle Positivo (GCP) - espécime ํo 2 .70 


\section{LISTA DE TABELAS}

Tabela 4.2.1 -Critério de Avaliação Radiográfica

Tabela 5.1 - Médias de volume de material obturador extruído dos grupos experimentais, expressos em $\mu \mathrm{l}$

Tabela 5.2 - Teste de Análise de Variância (ANOVA) das médias dos volumes de material obturador extruído dos grupos experimentais

Tabela 5.3 - Somas das freqüências da extrusão visual com as respectivas percentagens

Tabela 5.4 - Teste de Mann-Whitney das freqüências da extrusão visual entre os pares dos grupos experimentais

Tabela 5.5 - Somas das freqüências dos escores, da avaliação radiográfica final da obturação nos grupos experimentais dos dois examinadores

Tabela 5.6 - Teste de Mann-Whitney das avaliações radiográficas entre os pares dos grupos experimentais, nos sentidos vestíbulo-lingual e mésio-distal

Tabela 5.7 - Teste de Dunnet das avaliações radiográficas entre os pares dos grupos experimentais para cada escore, nos sentidos vestíbulolingual e mésio-distal

Tabela Ap.1 - Valores de volume, antes e após a obturação e diferença entre as duas mensurações, indicando o volume de material obturador extruído, expresso em microlitros $(\mu \mathrm{l})$, no grupo experimental G1 (Thermafil) 
Tabela Ap.2- Valores de volume, antes e após a obturação e diferença entre as duas mensurações, indicando o volume de material obturador extruído, expresso em microlitros $(\mu \mathrm{l})$, no grupo experimental G2 (Obtura II)

Tabela Ap.3-Valores de volume, antes e após a obturação e diferença entre as duas mensurações, indicando o volume de material obturador extruído, expresso em microlitros $(\mu \mathrm{l})$, no grupo experimental G3 (Ultrafil 3D)

Tabela Ap.4 - Valores de volume, antes e após a obturação e diferença entre as duas mensurações, indicando o volume de material obturador extruído, expresso em microlitros $(\mu \mathrm{l})$, no grupo experimental G4 (Fusionada)

Tabela Ap.5- Valores de volume, antes e após a inserção do cone principal de guta-percha e diferença entre as duas mensurações, indicando o volume de material obturador extruído, expresso em microlitros $(\mu \mathrm{l})$, no grupo controle negativo (GCN)

Tabela Ap.6-Valores de volume, antes e após a inserção do cone principal de guta-percha e diferença entre as duas mensurações, indicando o volume de material obturador extruído, expresso em microlitros $(\mu \mathrm{l})$, no grupo controle positivo (GCP)

Tabela Ap.7-Volume do material obturador extruído, expresso em microlitros $(\mu \mathrm{l})$

Tabela Ap.8-Teste de aderência à curva normal para os volumes de material obturador extruído dos grupos experimentais

Tabela Ap.9- Freqüências da extrusão visual de guta-percha e/ou cimento nos grupos experimentais, expressos em valores

Tabela Ap.10-Teste de $t$ de Student das médias das proporções da extrusão visual de cimento e guta-percha em comparação com cimento nos grupos experimentais G1 (Thermafil) e G4 (Fusionada)

Tabela Ap.11-Teste de Kruskat-Wallis das freqüências da extrusão visual dos grupos experimentais 
Tabela Ap.12-Freqüências da avaliação radiográfica final da obturação nos grupos experimentais do Examinador I, expressos em escores

Tabela Ap.13-Freqüências da avaliação radiográfica final da obturação nos grupos experimentais do Examinador II, expressos em escores

Tabela Ap.14-Teste dos Postos Sinalizados de Wilcoxon das avaliações radiográficas entre os dois examinadores, para cada grupo experimental nos sentidos vestíbulo-lingual e mésio-distal

Tabela Ap.15-Teste de KruskatWallis das avaliações radiográficas dos grupos experimentais nos sentidos vestíbulo-lingual e mésiodistal

Tabela Ap.16-Teste de Análise de Variância (ANOVA) das proporções de escores das avaliações radiográficas dos grupos experimentais, nos sentidos vestíbulo-lingual e mésio-distal

Tabela Ap.17-Teste dos Postos Sinalizados de Wilcoxon das avaliações radiográficas, entre os sentidos vestíbulo-lingual e mésio-distal nos grupos experimentais 


\section{LISTA DE ABREVIATURA E SIGLAS}

ANOVA Análise de Variância

cm centímetros

Com. Comércio

CRT Comprimento Real de Trabalho

G.L. Grau de Liberdade

H0 Hipótese de nulidade

Ind. Indústria

INMETRO Instituto Nacional de Metrologia, Normalização e Qualidade Industrial

M Média 
miligramas

$\mathrm{ml}$

mililitros

$\mathrm{mm}$

milímetros

PVC Cloreto de Polivinila

Sig. Significância

$\mu \mathrm{l} \quad$ microlitros 


\section{LISTA DE SÍMBOLOS}

${ }^{\circ} \mathrm{C} \quad$ graus Celsius

F teste estatístico

$\% \quad$ percentagem

p significância

s desvio padrão

t teste estatístico 


\section{SUMÁRIO}

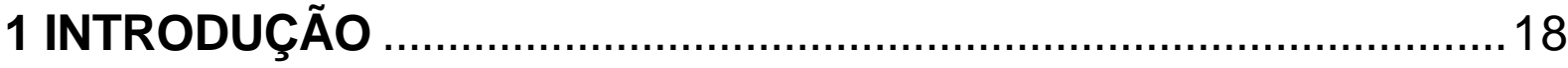

2 REVISÃO DA LITERATURA....................................................... 21

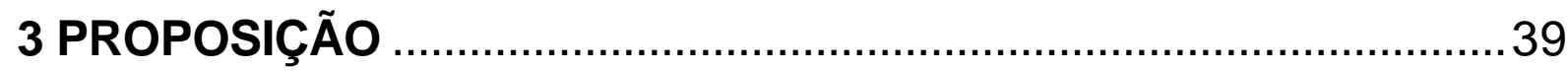

4 MATERIAL E MÉTODOS ........................................................ 41

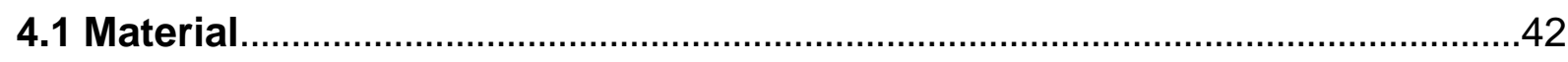

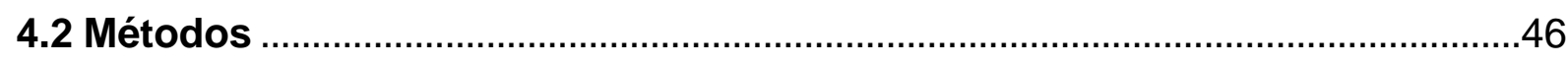

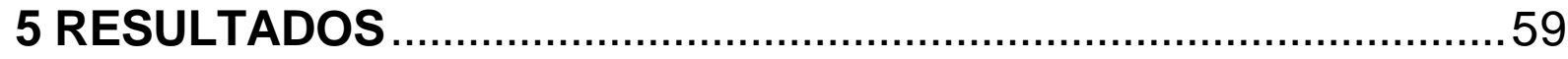

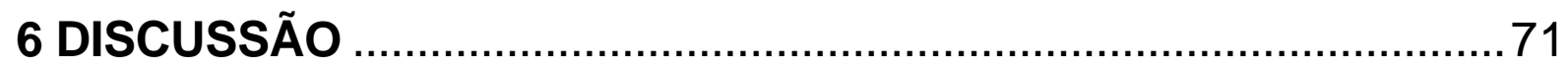



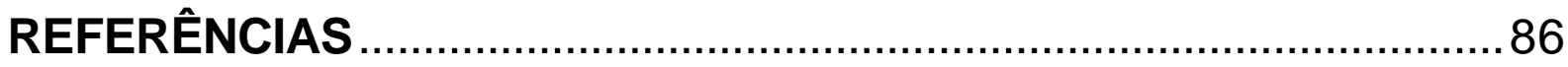

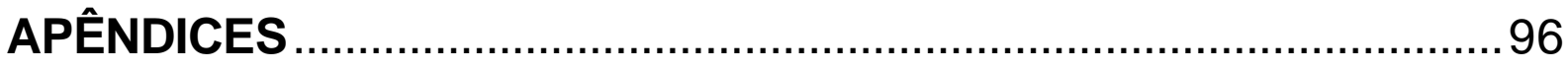

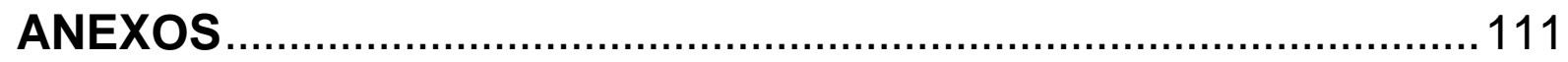


1 INTRODUÇÃO 


\section{INTRODUÇÃO}

O sucesso da terapia endodôntica é alcançado graças a uma seqüência de etapas bem realizadas, desde o diagnóstico, cirurgia de acesso e odontometria, bem como, às manobras de preparo químico-cirúrgico e obturação do canal radicular.

Porém, em nada adiantaria realizarmos adequadamente todas as etapas anteriores à obturação se, nesta fase, não fosse alcançado seu principal objetivo, que consiste em promover um selamento tridimensional, no intuito de não só impedir a comunicação do meio externo com a região periapical, como ambém preservar a sanificação alcançada durante a fase de preparo do canal e evitar que microorganismos e exsudatos da região apical invadam o espaço do canal radicular, permitindo, assim, que o selamento biológico apical seja alcançado.

Em relação ao material obturador, após a sua introdução por Bowman ${ }^{1}$ (1867, apud MILAS, 1982), a guta-percha em forma de pontas tem sido ainda amplamente utilizada como material sólido de escolha, em decorrência de suas características físicas, químicas e biológicas.

Atualmente, diversas técnicas têm sido desenvolvidas no intuito de melhorar a adaptação dos materiais obturadores às paredes do sistema de canais

\footnotetext{
${ }^{1}$ Bowman GA. History of dentistry in Missouri. The Ovid Press Inc 1938.
} 
radiculares, dentre as quais, as que utilizam a guta-percha plastificada termicamente com modernos e sofisticados sistemas de obturação, tais como, Alphaseal, JS Quick Fill, Microseal, Obtura II, Successfil, System B, Ultrafil, Thermafil, Touch'n Heat, e Trifecta.

As principais vantagens da guta-percha termoplastificada baseiam-se na facilidade técnica e redução no tempo de trabalho operatório na fase de obturação, reprodução detalhada da anatomia interna do canal, bem como, homogeneidade do material obturador.

Porém, apesar da eficiência no selamento tridimensional com o uso destas técnicas, há dificuldade no controle longitudinal durante a obturação, que poderia acarretar em extrusão do material obturador em direção aos tecidos perirradiculares, provocando um desconforto no pós-operatório, interferindo sobremaneira na reparação da região periapical (INGLE; WEST, 1994; NGUYEN; RUDDLE, 1994; WALTON; JOHNSON, 1997).

Deste modo, é de grande relevância o estudo comparativo dos diferentes aparelhos e técnicas de obturação termoplastificada, avaliando, entre estes, quais produzirão quantitativamente menor extravasamento apical do material obturador, relacionando com a freqüência da extrusão de guta-percha e/ou cimento e a qualidade final da obturação. 
2 REVISÃO DA LITERATURA 


\section{REVISÃO DA LITERATURA}

Há necessidade de se obter, durante o tratamento endodôntico, uma adequada adaptação do material obturador ao preparo do canal radicular, promovendo, assim, um selamento tridimensional, sem causar o extravasamento deste material à região periapical (GULABIVALA, 1996), pois, a sobreobturação é um dos fatores que influencia no insucesso da terapia endodôntica (GUTMANN, 1992; GUTMANN; HOVLAND, 1999).

Neste aspecto, Swartz, Skidmore e Griffin (1983) comprovaram em estudo realizado na Universidade da Virgínia, através de avaliação clínica e radiográfica de 1007 dentes tratados endodonticamente, que o índice de insucesso em dentes sobreobturados foi significativamente maior $(36,59 \%)$ do que em dentes obturados aquém do vértice radiográfico (8,10\%), demonstrando, assim, a necessidade de manter os materiais de obturação confinados no interior do canal radicular.

Halse e Molven (1987) avaliaram radiograficamente o tratamento endodôntico de 239 pacientes por um período de 10 a 17 anos, verificando que a freqüência de sucesso foi menor nos casos de sobreobturações (76\%), do que nos grupos em que não ocorreu extrusão de material obturador (83\%). Os autores constataram, também, que a incidência de sucesso mostrou depender da extensão do material obturador extruído, aumentando significativamente o índice 
de falhas (53\%) nas espécimes com mais de $2 \mathrm{~mm}$ de material obturador extruído, demonstrando que a reparação foi severamente influenciada pela persistência do material extruído.

Seltzer (1988), assim como Walton e Johnson (1997) afirmaram que, das três condições de obturação do canal radicular, aquém, além e no limite do vértice radiográfico, a sobreobturação produz a maior incidência de falhas, obtendo, portanto, menores índices de sucessos.

Odesjo et al. (1990) realizaram avaliação radiográfica de 1492 dentes tratados endodonticamente da população da Suécia, constatando que obturações com adequado selamento, porém com excesso de material obturador além do ápice, mostraram significativamente maior incidência de lesões periapicais (56\%), em comparação aos dentes obturados nos limites adequados, que apresentaram $17,4 \%$ de insucessos.

Ainda em 1990, Sjogren et al., avaliando o tratamento endodôntico, clínica e radiograficamente, em 356 pacientes por um período de prosservação de 8 a 10 anos, verificaram alto índice de insucessos (24\%) em canais sobreobturados, portadores de polpas necróticas e lesão periapical.

Smith, Setchell e Harty (1993), em estudo retrospectivo de 821 dentes, através de análise radiográfica, também constataram que o grau de insucesso em dentes sobreobturados $(25 \%)$ foi significativamente maior que em dentes obturados aquém do vértice radiográfico (13,05\%).

Saunders et al. (1997), em análise radiográfica de 340 pacientes por um período de 10 anos após o tratamento endodôntico, constataram que houve um aumento estatisticamente significante nas radiolucências periapicais, em obturações de canais radiculares além do ápice radiográfico. 
Com o advento da obturação endodôntica com guta-percha termoplastificada, vários autores comprovaram em seus estudos que estas técnicas possuem efetiva capacidade de selamento apical, melhorando a adaptação do material obturador nas paredes do sistema de canais radiculares, entre as quais: Alphaseal (GULABIVALA; HOLT; LONG, 1998; GILHOOLY et al., 2000), Microseal (REZENDE; BOMBANA, 1999; DAVALOU; GUTMANN; NUNN, 1999), Obtura II (SMITH et al., 2000), System B (DAVALOU; GUTMANN; NUNN, 1999; SMITH et al., 2000), Ultrafil (OLSON; HARTWELL; WELLER, 1989; MOURA et al., 1989; MOURA, 1990; AL-DEWANI; HAYES; DUMMER, 2000a), Thermafil (CLARK; ELDEEB, 1993; DUMMER et al., 1993; GUTMANN et al., 1993a, 1993b; DUMMER et al., 1994), Touch'n Heat (SILVER; LOVE; PURTON, 1999; FAN; WU; WESSELINK, 2000) e Trifecta (LLOYD et al., 1995; AL-DEWANI; HAYES; DUMMER, 2000b).

Porém, nas técnicas de obturação que utilizam guta-percha termoplastificada existem dificuldades no controle longitudinal, trazendo como conseqüência a extrusão apical, que agride a região periapical pela presença física do material obturador, influenciando na reparação pós tratamento endodôntico, em virtude do desencadeamento de intensas reações inflamatórias iniciais e posteriormente reações crônicas de corpo estranho (LANGELAND et al., 1987; MOLYVDAS et al., 1989; INGLE; WEST, 1994; TAVARES; SOARES; SILVEIRA, 1994; RICUCCI; LANGELAND, 1998), que promovem um atraso na reparação dos tecidos adjacentes ao material extruído (GUTIERREZ; GIGOUX; ESCOBAR, 1969; BERGENHOLTZ et al., 1979).

Por outro lado, em casos mais severos, o material obturador extruído pode provocar danos químicos e mecânicos em estruturas anatômicas adjacentes aos 
ápices dos dentes envolvidos, tais como, parestesia do nervo mentoniano, osteomielite aguda e crônica, fatos estes relatados por Barkhordar e Nguyen (1985) e Gatot, Peist e Mozes (1989), respectivamente.

Em virtude da intensa comercialização e conseqüente utilização clínica dos aparelhos e sistemas de obturação com guta-percha termoplastificada, houve grande preocupação por parte dos pesquisadores em relação à extrusão apical do material obturador na região perirradicular, visto que, segundo Gutmann e Hovland (1999), não existem estudos longitudinais ou retrospectivos que justifiquem a colocação intencional da guta-percha e cimento durante a obturação, além dos limites do sistema de canais radiculares.

Neste aspecto, Yee et al., desde 1977, com a introdução do 1ำ dispositivo de guta-percha termoplastificada com seringa de pressão na temperatura de $160^{\circ} \mathrm{C}$ aquecida em bico de Bunsen, constataram através de exame visual, radiográfico e microscópio eletrônico de varredura, em experimento in vitro, que a extrusão de guta-percha ocorreu quando da utilização do sistema com agulhas de calibres menores, chegando mais próximo da região apical.

Mais tarde, este dispositivo começou a ser comercializado através dos sistemas Ultrafil e Obtura, modificados posteriormente para Ultrafil 3D e Obtura II, respectivamente.

Johnson, em 1978, introduziu a técnica de obturação tridimensional que eliminava a adaptação de um cone principal de guta-percha, utilizando lima de aço inoxidável atuando como elemento carregador metálico de guta-percha e cimento, mostrando ser um método simples, rápido e eficiente na obturação do sistema de canais radiculares, porém constatou a extrusão de material obturador em alguns casos clínicos, através da análise radiográfica. 
Posteriormente, esta técnica foi aperfeiçoada e inserida no mercado através do sistema Thermafil.

Marlin et al. (1981) observaram in vivo o sucesso clínico da técnica de injeção de guta-percha termoplastificada através de unidade de controle elétrico de temperatura, com resultados comparáveis à técnica convencional, em avaliações radiográficas no período de 6 a 12 meses após obturação endodôntica, verificando, também, que em alguns casos ocorreu a extrusão de guta-percha na região apical.

EIDeeb em 1985, avaliando in vitro a freqüência de sobreobturações produzidas pelas técnicas de condensação lateral e injeção de guta-percha termoplastificada, recomendada por Marlin et al. (1981), concluiu que a técnica de injeção associada à condensação vertical resultou em alta incidência (75\%) de extrusão de guta-percha, em comparação com a condensação lateral (0\%).

Evans e Simon, em 1986, constataram in vitro, através de microscópio eletrônico de varredura, a extrusão apical de material obturador em canais obturados pela técnica Obtura com a utilização de cimento, tanto na presença, como na ausência de magma dentinário.

Ainda em 1986, Marlin verificou radiograficamente, em relato de caso clínico, a extrusão apical de cimento na raiz distal de um molar inferior, utilizando a técnica Obtura na obturação do sistema de canais radiculares.

George, Michanowicz e Michanowicz (1987) verificaram in vitro, através de avaliação radiográfica, que canais obturados com o sistema Ultrafil sem confecção de barreira apical, exibiram significativa extrusão de guta-percha via forame apical (100\% dos espécimes), enquanto que nos espécimes com matriz dentinária apical não houve extrusão de material obturador. 
Mann e McWalter, também em 1987, avaliaram in vitro, através de estereomicroscópio, a incidência e extensão da extrusão de guta-percha em canais obturados por condensação lateral e sistema Obtura, concluindo que, somente na técnica de injeção de guta-percha termoplastificada, ocorreram sobreobturações, em $25 \%$ dos espécimes, sendo $15 \%$ em canais curvos e $10 \%$ em canais retos, variando de 0,5 a 2,0mm a extensão de material obturador além do forame apical.

Langeland et al., em 1987, avaliaram in vivo a eficácia das técnicas Ultrafil e Obtura de canais obturados em dentes de macacos, constatando radiograficamente que, na ausência de stop apical em ambas as técnicas, ocorreu a sobreobturação e confirmado histologicamente, através de microscopia, que em nenhuma técnica obteve-se controle apical, sendo que o material extruído além do forame causou reação inflamatória aguda, em curto período, e reação de corpo estranho, em longos períodos de avaliação.

Neste mesmo ano, Gutmann e Rakusin, baseados em revisão de literatura e experiência clínica, identificaram os principais problemas do sistema Obtura, enfatizando a falta de controle longitudinal na injeção da guta-percha termoplastificada, havendo necessidade da presença de matriz apical para evitarse a extrusão do material obturador.

Assim, Ritchie, Anderson e Sakamura (1988) investigaram, através de pesagem em balança analítica, a extrusão apical de guta-percha termoplastificada e/ou cimento, em canais simulados com patência apical de $0,20 \mathrm{~mm}$ e 0,40mm, obturados com o sistema Obtura, técnicas mistas de plug apical de guta-percha com clorofórmio e plug apical de cones de prata, associadas ao sistema Obtura. Os autores verificaram que com $0,20 \mathrm{~mm}$ de abertura apical houve pouca extrusão 
nas técnicas estudadas, não sendo estatisticamente significante, porém, com 0,40mm o sistema Obtura apresentou significativa extrusão $(2,83 \mathrm{mg})$ em relação a técnica de plug apical $(1,94 \mathrm{mg})$, concluindo que a quantidade de material extruído foi diretamente proporcional à área de abertura foraminal, bem como, enfatizando a necessidade da realização de um plug apical em canais radiculares com amplos forames, para prevenir a extrusão da guta-percha termoplastificada.

LaCombe et al. (1988) verificaram in vitro, através de microscópio eletrônico de varredura, o controle longitudinal de obturações de canais radiculares produzidas pelas técnicas de condensação lateral, Obtura e Ultrafil, constatando que a sobreobturação no grupo Ultrafil foi significativamente maior do que os espécimes obturados por condensação lateral, porém não houve diferença estatisticamente significante na extrusão de material obturador do grupo Obtura em relação ao Ultrafil.

Por outro lado, Olson, Hartwell e Weller em 1989, avaliando in vitro através de estereomicroscópio, o selamento apical de canais radiculares com patência de 0,42mm, obturados pelas técnicas de condensação lateral, Obtura e Ultrafil após a inserção de um cone principal de guta-percha com cimento, verificaram um baixo índice de extrusão de material obturador na técnica Ultrafil $(6,6 \%)$, bem como, nenhuma incidência nos grupos Obtura e condensação lateral.

Michanowicz et al. (1989), avaliando radiograficamente a efetividade clínica de obturações de canais radiculares realizadas com a técnica de injeção de gutapercha termoplastificada (Ultrafil) por um período de 24 meses, verificaram mínima extrusão de guta-percha em virtude da manutenção da integridade do forame apical, com cuidados especiais no estabelecimento do comprimento de trabalho, bem como, no preparo do canal sem realização de patência apical. 
Lares e EIDeeb (1990) constataram alta incidência de extrusão de cimento nos canais radiculares obturados in vitro pela técnica Thermafil com carregador metálico em comparação com a técnica de condensação lateral em que não houve extrusão de material obturador.

Moura (1990), avaliando em microscopia eletrônica de varredura a qualidade de obturações de canais radiculares em dentes extraídos, realizadas através da técnica convencional sem preparo apical e sistema Ultrafil, sem e com o uso de cones de guta-percha seccionados na região apical, verificou que as obturações realizadas somente com o sistema Ultrafil sem o uso de cones seccionados, apesar de apresentarem boa adaptação às paredes do canal radicular, mostraram grande tendência de extrusão apical de guta-percha (56\%).

Haddix et al. em 1991, avaliando in vitro a capacidade de selamento apical do Thermafil carregador metálico, em comparação com a técnica de condensação lateral, constataram visualmente que os dentes obturados com a técnica de gutapercha termoplastificada exibiram extrusão de guta-percha em $100 \%$ das espécimes.

Ainda em 1991, Budd, Weller e Kulild comparando in vitro através de estereomicroscópio, a qualidade de obturações de canais radiculares estandardizados, realizadas com as técnicas de condensação lateral, Obtura e Ultrafil nas três consistências de guta-percha (Regular Set, Endo Set e Firm Set), constataram extrusão freqüente de guta-percha nas técnicas termoplastificadas, em função das características superiores de escoamento destes materiais em comparação à condensação lateral.

Scott e Vire, em 1992, avaliaram quantitativamente através de pesagem em balança analítica, a extrusão de guta-percha e/ou cimento nas técnicas 
Obtura, Ultrafil, Touch'n Heat e Thermafil carregador metálico, utilizando 80 incisivos centrais humanos extraídos, preparados com patência apical com e sem a confecção de plug dentinário apical. Os autores concluíram que, com o plug de dentina não houve diferença estatística na extrusão de material obturador entre as técnicas, sendo um efetivo meio na redução da sobreobturação. Porém, quando a patência apical foi mantida desobstruída, a técnica Thermafil teve significativamente maiores quantidades de material obturador extruído $(0,0092 \mathrm{~g})$ em comparação ao Ultrafil $(0,0024 g)$, Touch'n Heat $(0,0007 g)$ e Obtura $(0,0001 g)$.

Em 1993, Clark e EIDeeb estudaram in vitro a incidência de extrusão apical de guta-percha em obturações de canais radiculares utilizando o sistema Thermafil com carregadores de plástico e de metal, em comparação com a técnica de condensação lateral, concluindo que, com o sistema Thermafil, tanto o carregador de plástico como o de metal produziram um aumento significante na incidência de extrusão apical da guta-percha em comparação à condensação lateral, sendo maior a freqüência em canais retos (85 a 95\%) do que em canais curvos (45\%), principalmente com a utilização do carregador metálico.

No mesmo ano, Dummer et al. compararam a qualidade da obturação de canais radiculares em dentes humanos extraídos usando as técnicas de condensação lateral e Thermafil com carregador metálico, concluindo que a extrusão apical do cimento e guta-percha foi altamente significativa nos espécimes obturados com Thermafil.

Soares e Rocha (1993) avaliando in vitro, através de análise radiográfica, o nível apical de obturações realizadas com o sistema Ultrafil com e sem cimento obturador, verificaram alta incidência de extrusão apical tanto nos espécimes obturados com cimento (75\%) quanto no grupo sem cimento $(87,5 \%)$. 
Gutmann et al. (1993a) verificaram, através de análise radiográfica, a adaptação do material obturador após realização de patência apical, em molares inferiores extraídos, obturados com Thermafil carregador plástico e condensação lateral a frio, concluindo que, com a patência do forame apical, a técnica Thermafil apresentou significativa maior incidência de extrusão do material obturador.

Ainda Gutmann et al. (1993b) também constataram, através de estereomicroscópio, maior incidência de extrusão de material obturador com a utilização in vitro do Thermafil carregador plástico em comparação com a técnica de condensação lateral, confirmando assim os resultados do estudo radiográfico realizado anteriormente.

Porém, Gençoglu, Samani e Gunday (1993) avaliando, através de microscópio eletrônico de varredura, a infiltração marginal apical em 120 dentes humanos extraídos, obturados pelas técnicas de condensação lateral, Ultrafil e Thermafil carregador metálico, posteriormente implantados em subcutâneo de ratos por 90 dias, constataram a extrusão de cimento em apenas 2 espécimes obturados com injeção de guta-percha termoplastificada.

Leung e Gulabivala (1994b), estudando in vitro a influência da variação de temperatura de plastificação da guta-percha no sistema Thermafil em relação à capacidade de selamento apical de canais radiculares, constataram em microscopia óptica que, com o Thermafil plastificado na chama e em temperaturas de $60^{\circ} \mathrm{C}, 75^{\circ} \mathrm{C}$ e $90^{\circ} \mathrm{C}$, houve extrusão de cimento em todos os espécimes, porém, extrusão de quantidades substanciais de guta-percha não foram freqüentes.

Ainda Leung e Gulabivala (1994a), avaliando in vitro o selamento apical de obturações endodônticas realizadas pelas técnicas de condensação lateral e 
Thermafil carregador metálico, constataram visualmente a extrusão muito freqüente de cimento em relação à menor incidência de extrusão apical de gutapercha na técnica Thermafil.

Berger (1995), avaliando os resultados clínicos em 14 pacientes com obturações endodônticas realizadas pelas técnicas Thermafil e condensação lateral, constatou radiograficamente a extrusão de material obturador em 2 casos, utilizando o Thermafil carregador plástico em canais atresiados.

Neste mesmo ano, Holland et al., analisando in vitro o selamento apical das três consistências de guta-percha do sistema Ultrafil (Regular Set, Firm Set e Endo Set) em comparação com a técnica de condensação lateral, verificaram visualmente um baixo índice de extravasamento de material obturador em todos os tipos de guta-percha do sistema Ultrafil (10\% no Regular Set e $20 \%$ no Firm Set e Endo Set), não ocorrendo extrusão apical nos espécimes obturados por condensação lateral.

Lloyd et al. em 1995, estudaram in vitro o selamento e a incidência de extrusão apical em canais obturados pelas técnicas de condensação lateral a frio e Trifecta com ou sem magma dentinário, concluindo que a extrusão apical de cimento e guta-percha ocorreu com freqüência em todos os grupos, porém, houve significativa maior incidência na extrusão de cimento na técnica Trifecta quando comparada à condensação lateral, independentemente da presença ou ausência de magma dentinário.

Santa Cecilia, Moraes e Berbert (1995) avaliaram in vitro a incidência da extrusão apical de guta-percha e/ou cimento, através de observação visual em canais obturados com as técnicas Thermafil e condensação lateral, concluindo 
que houve significativo maior extravasamento de material nos canais retos obturados com Thermafil.

Ainda em 1995, Utrilla et al., avaliando histologicamente obturações de canais radiculares em dentes de cães realizadas pelas técnicas Ultrafil e McSpadden, constataram microscopicamente extravasamento apical somente no grupo Ultrafil em $52,4 \%$ dos espécimes. Os autores verificaram que, em todos os casos com extrusão de material obturador, não ocorreu o selamento biológico apical.

Holtz e Machado (1998) avaliaram quantitativamente, através de pesagem em balança analítica, o extravasamento apical de guta-percha em canais simulados, obturados com a técnica Successfil sem cimento em forames apicais com diferentes padronizações de diâmetro (15 ao 40). Os autores concluíram que houve extrusão de guta-percha em todos os grupos, porém, os diâmetros 15 $(0,0006 \mathrm{~g}), 20(0,0001 \mathrm{~g})$ e $25(0,0008 \mathrm{~g})$ não foram estatisticamente significantes em comparação aos diâmetros $30(0,0016 \mathrm{~g}), 35(0,0012 \mathrm{~g})$ e $40(0,0024 \mathrm{~g})$, em que as diferenças das médias dos pesos do material extruído foram altamente significativas.

Gulabivala, Holt e Long (1998) compararam a qualidade do selamento apical, o tempo de obturação e a extrusão de guta-percha e cimento em canais obturados in vitro, usando a técnica de condensação lateral a frio e três métodos de guta-percha termoplastificada (Alphaseal, Thermafil e JS Quick Fill), concluindo que em todos os grupos houve extrusão de material obturador, de modo que as técnicas Alphaseal e Thermafil apresentaram as maiores incidências de espécimes com extrusão de guta-percha e cimento, mostrando diferenças estatisticamente significantes em relação aos demais grupos. 
Davalou, Gutmann e Nunn (1999), estudando em estereomicroscópio a infiltração marginal apical em dentes humanos extraídos obturados com o System B e Microseal, constataram a extrusão apical de guta-percha e/ou cimento variando entre 0,5 a $1,5 \mathrm{~mm}$, em aproximadamente $30 \%$ dos espécimes do grupo Microseal.

Kytridou, Gutmann e Nunn (1999), em estudo de infiltração marginal apical, verificaram radiograficamente a incidência de extrusão de material obturador em raízes mesiais de molares inferiores extraídos, utilizando técnicas de obturação termoplastificada, Thermafil e System B na ausência de magma dentinário, concluindo que o Thermafil demonstrou maior incidência de canais radiculares com material obturador extruindo através do ápice (84\%) em comparação ao System B (43\%).

Moura, Otani e Davidowicz (1999/2000) propuseram modificações na técnica de obturação com o uso do sistema Ultrafil, denominada técnica da gutapercha Fusionada, utilizando um cone mestre de guta-percha estandardizado, calibrado e fundido com a guta-percha termoplastificada a baixa temperatura, concluindo que houve um maior controle na sobreobturação em virtude do transportador sólido ser um cone mestre de guta-percha.

Al-Dewani, Hayes e Dummer (2000b), analisando a qualidade da obturação de canais radiculares em dentes humanos extraídos usando as técnicas de condensação lateral e sistema Trifecta, concluíram que o grupo Trifecta mostrou significativa maior incidência de extrusão apical de cimento em comparação à condensação lateral; por outro lado, em ambas as técnicas houve baixo índice de extrusão de guta-percha. 
Também em 2000, Gilhooly et al., avaliando o selamento apical e a qualidade radiográfica de obturações de canais radiculares em dentes humanos extraídos, usando as técnicas de condensação lateral e guta-percha aquecida multifase (Alphaseal), constataram visualmente que o Alphaseal multifase teve maior incidência de extrusão de cimento e guta-percha em relação à técnica de condensação lateral, diferença esta altamente significativa.

Ainda, Al-Dewani, Hayes e Dummer (2000a) verificaram in vitro a incidência de extrusão apical de material obturador em canais obturados pelas técnicas de condensação lateral a frio e sistema Ultrafil, concluindo que os espécimes obturados com guta-percha termoplastificada à baixa temperatura (Ultrafil) apresentaram significativamente maior freqüência de extrusão apical de cimento e guta-percha, em comparação à condensação lateral a frio.

Em 2001, novamente Gilhooly et al., avaliando também o selamento apical e a qualidade radiográfica de obturações de canais radiculares em dentes extraídos, porém neste estudo usando as técnicas de condensação lateral e gutapercha aquecida fase alpha (Alphaseal) em conjunto com cone único, constataram visualmente que o grupo Alphaseal teve significativamente maior incidência de extrusão de cimento em relação à condensação lateral, embora em ambos os grupos houve extrusão de guta-percha, diferença esta não estatisticamente significante.

Kastakova, Wu e Wesselink (2001) avaliaram quantitativamente o peso do material obturador extruído, através de balança analítica, em caninos extraídos e obturados com as técnicas de condensação lateral e condensação vertical térmica (Touch'n Heat) associado ao Ultrafil, com e sem a confecção de matriz apical durante o preparo químico-cirúrgico do canal, concluindo que a realização de 
matriz apical não influenciou estatisticamente na extrusão da guta-percha e cimento, porém, os autores constataram que os canais com matriz apical extruíram significativamente mais material nos espécimes obturados com Touch’n Heat $(2,45 \mathrm{mg})$ do que na condensação lateral $(0,95 \mathrm{mg})$.

Entretanto, Abarca, Bustos e Navia (2001) compararam in vitro as técnicas de condensação lateral e Thermafil, com relação ao selamento apical e extrusão de material obturador em raízes mesiais curvas de molares inferiores, verificando que a diferença na incidência de extrusão de guta-percha e/ou cimento, em 25\% na técnica Thermafil e $10 \%$ nos canais obturados por condensação lateral, não foi estatisticamente significante.

Wu, Sluis e Wesselink, em 2002, avaliaram in vitro, através de microscopia, a influência da profundidade de aplicação do calor durante a compactação vertical aquecida sem cimento (Touch'n Heat), em relação à incidência da extrusão apical e o peso do material obturador extruído em balança analítica. Os autores verificaram que a guta-percha extruiu em 12\% dos espécimes, independentemente da profundidade de aquecimento $(2 \mathrm{~mm}$ ou $4 \mathrm{~mm}$ aquém do forame apical), apesar da maior incidência de extrusão em $2 \mathrm{~mm}$ (5 espécimes), a quantidade de material extruído foi pequena $(0,4 \mathrm{mg})$, não havendo diferença estatisticamente significante entre os dois níveis de profundidade.

Ainda em 2002, Schafer e Olthoff, avaliando in vitro o efeito de diferentes cimentos endodônticos no selamento apical de canais retos e curvos obturados por condensação lateral e Thermafil com carregador plástico, constataram visualmente que os espécimes do grupo Thermafil apresentaram maior freqüência de extrusão de material obturador, diferença altamente significativa em relação à condensação lateral. Os autores verificaram, também, que não houve diferença 
estatisticamente significante na extrusão apical entre os diferentes cimentos utilizados.

Silva et al. (2002) compararam, em canais simulados, a extrusão apical de guta-percha e cimento através de estereomicroscópio entre as técnicas de condensação lateral, Thermafil com carregador plástico e condensação lateral associada à obturação reversa com Thermafil. Os autores verificaram que não houve diferença estatisticamente significante na extrusão de cimento entre os grupos de condensação lateral e obturação reversa com Thermafil, bem como, não ocorreu extrusão de guta-percha nestes grupos, enquanto que a técnica Thermafil resultou em $100 \%$ de espécimes com extrusão de guta-percha e cimento, diferença esta altamente significativa em relação aos demais grupos.

Mais recentemente, Levitan, Himel e Luckey (2003), estudando in vitro a qualidade e a extensão apical de obturações realizadas com a técnica Thermafil, variando a velocidade de inserção do carregador plástico, verificaram, através de estereomicroscópio, que quanto mais rápida a inserção (1 segundo), maior a incidência de extrusão apical, diferenças estatisticamente significantes em relação às demais velocidades. Porém, apesar da menor freqüência de sobreobturações na inserção lenta (6 segundos), este grupo falhou na reprodução das irregularidades do canal. Assim, os autores concluíram que na técnica Thermafil deve-se tentar obter um controle na extensão apical sem sacrificar a qualidade tridimensional da obturação.

Portanto, pelo exposto, constata-se que vários estudos foram realizados verificando a extrusão apical em diversas técnicas, principalmente através de análises qualitativas, cabendo, no momento, avaliar a extrusão apical, em diferentes técnicas de obturação termoplastificada, com a introdução de uma nova 
metodologia quantitativa relacionando com a freqüência da extrusão e a qualidade da obturação através da radiografia convencional. 
3 PROPOSIÇÃO 


\section{PROPOSIÇÃO}

Amparados no exposto, foi nosso intuito avaliar in vitro a extrusão apical de quatro técnicas de obturação termoplastificada, Thermafil, Obtura II, Ultrafil 3D e Fusionada, através de uma nova metodologia de mensuração de volume do material obturador extruído, relacionando com a freqüência da extrusão visual de guta-percha e/ou cimento e a qualidade radiográfica final da obturação. 
4 MATERIAL E MÉTODOS 


\section{MATERIAL E MÉTODOS}

\subsection{Material}

4.1.1 Água destilada (Sidepal Ind. Com.), Brasil

4.1.2 Bomba à vácuo (Nevoni), Brasil

4.1.3 Brocas esféricas carbide nํㅜ 2, 4 e 6 (FGSorensen), Brasil

4.1.4 Brocas tipo Batt nº 12 e 16 (Maillefer - Dentsply), Suíça

4.1.5 Brocas tipo Gates-Glidden nํ2, 3 e 4 (Maillefer - Dentsply), Suíça

4.1.6 Câmara escura de revelação (VH Midas Dental Products), Brasil

4.1.7 Caneta em alta rotação (Dabi-Atlante), Brasil

4.1.8 Cânula metálica de aspiração (Konnen Ind. Com.), Brasil

4.1.9 Cânulas de guta-percha FirmSet (Ultrafil - Hygenic Corporation), USA

4.1.10 Cera utilidade (Epoxiglass Ind. Com. de Produtos Químicos), Brasil

4.1.11 Cimento N-Rickert (Fórmula \& Ação Laboratório Farmacêutico), Brasil

4.1.12 Colgadura unitária para filme radiográfico (Tecnodent Ind. Com.), Brasil

4.1.13 Cones de papel absorvente .04 (Dentsply - Maillefer), Brasil

4.1.14 Cones de guta-percha principais estandardizados .02 nำ 15 (Dentsply Maillefer), Brasil 
4.1.15 Cones de guta-percha principais estandardizados .04 (Dentsply Maillefer), Brasil

4.1.16 Contra-ângulo em baixa rotação (Dabi-Atlante), Brasil

4.1.17 Creme de Endo-PTC (Polidental Ind. Com.), Brasil

4.1.18 Dentes incisivos centrais superiores humanos extraídos

4.1.19 Elástico ortodôntico separador (Morelli), Brasil

4.1.20 Endo Pro (VK Driller Equipamentos Elétricos), Brasil

4.1.21 Espaçador digital no FF (Moyco - Union Broach), USA

4.1.22 Espátula de inserção oㅡ 01 (SSWhite - Duflex), Brasil

4.1.23 Espátula flexível ํㅡㄴ 24 (SSWhite-Duflex), Brasil

4.1.24 Éster de cianoacrilato (Super Bonder - Loctite), Brasil

4.1.25 Filme radiográfico periapical (Kodak), Brasil

4.1.26 Filme transparente de PVC (Majipack - Inproco Ind. Com.), Brasil

4.1.27 Intermediário metálico (Konnen Ind. Com.), Brasil

4.1.28 Jogo de calcadores modelo Paiva ํㅜ 1,2 3 e 4 (Stainless Guth), Brasil

4.1.29 Lâmina de barbear (Gillette), Brasil

4.1.30 Lâminas de borracha (Tigre), Brasil

4.1.31 Limas tipo K no 10 e 15 (Maillefer - Dentsply), Suíça

4.1.32 Limas ProFile Orifice Shaper 3 (.06/40), ProFile Orifice Shaper 2 (.06/30), ProFile .06/25, ProFile .06/20, Profile conicidade .04 no 15, 20, 25, 30, 35, 40, 45 e 60 (Maillefer - Dentsply), Suíça

4.1.33 Lupa de 10 aumentos (VH Midas Dental Products), Brasil

4.1.34 Micromotor em baixa rotação (Dabi-Atlante), Brasil

4.1.35 Morsa de apreensão (IEL), Índia

4.1.36 Negatoscópio (VH Midas Dental Products), Brasil 
4.1.37 Obtura II (Obtura Corporation), USA

4.1.38 Pinça endodôntica tipo Perry (Stainless Guth), Brasil

4.1.39 Pinça hemostática reta tipo mosquito (Stainless Guth), Brasil

4.1.40 Pincéis de pelo de carneiro ํㅡ 8 e 14 (Tigre), Brasil

4.1.41 Placa de vidro despolida (Daufenbach \& Daufenbach), Brasil

4.1.42 Raio X - Spectro II (Dabi-Atlante), Brasil

4.1.43 Régua calibradora de cones (Maillefer - Dentsply), Suíça

4.1.44 Resina acrílica quimicamente ativada : pó Dencor no 66 e líquido Jet (Artigos Odontológicos Clássico), Brasil

4.1.45 Seringas plásticas descartáveis de 10ml (SR Produtos Hospitalares), Brasil

4.1.46 Sistema de mensuração de volume, ํo BU 3650 (LAMEVOL Laboratório de Metrologia Volumétrica, FGG - Equipamentos e Vidraria de Laboratório), Brasil

4.1.47 Solução de EDTA-T a 17\% (Fórmula \& Ação Laboratório Farmacêutico), Brasil

\subsubsection{Solução de fixador (Kodak), Brasil}

4.1.49 Solução de Hipoclorito de Sódio a 0,5 \% (Fórmula \& Ação Laboratório Farmacêutico), Brasil

\subsubsection{Solução de revelador (Kodak), Brasil}

4.1.51 Soro fisiológico - Solução de Cloreto de Sódio a 0,9\% (LBS Ind. Farmacêutica), Brasil

4.1.52 Stops de silicone (Maillefer - Dentsply), Suíça

4.1.53 Tesoura reta MT125 (Golgran), Brasil 
4.1.54 Thermafil no 60 (Maillefer - Dentsply -Tulsa Dental Products), USA

4.1.55 Thermaprep Plus (Maillefer - Dentsply - Tulsa Dental Products), USA

4.1.56 Ultrafil 3D (Hygenic Corporation), USA

4.1.57 Vaselina líquida (ADV - Laboratório Tayuyna), Brasil

4.1.58 Verifier .04/60 (Maillefer - Dentsply), Suíça 


\subsection{Métodos}

Foram selecionados 62 dentes incisivos centrais superiores humanos extraídos, do Banco de Dentes Permanentes Humanos da Faculdade de Odontologia da Universidade de São Paulo.

Os dentes escolhidos foram radiografados para confirmação da presença de canal único, ausência de qualquer sinal de calcificação, reabsorção ou tratamento endodôntico prévio e, a seguir, submersos em hipoclorito de sódio à 0,5\% por 48 horas, para remoção das estruturas orgânicas remanescentes, seguido por soro fisiológico no período mínimo de 72 horas, para reidratação.

A cirurgia de acesso e o preparo da câmara pulpar foram realizados, inicialmente com o auxílio de brocas esféricas em alta rotação e o preparo da entrada do canal com brocas tronco-cônicas tipo Batt e brocas tipo Gates-Glidden, ambas em baixa rotação (PAIVA; ANTONIAZZI, 1993).

Em seguida, realizourse o esvaziamento do canal radicular, através da introdução do instrumento tipo K nำ 10, da marca Maillefer - Dentsply e irrigação, utilizando $10 \mathrm{ml}$ de hipoclorito de sódio a 0,5\%, até a visualização da ponta do instrumento no limite do forame apical, com o auxílio de lupa de 10 aumentos. Neste momento, esta lima foi pinçada, por meio de uma pinça hemostática reta, em seu ponto de referência na borda incisal da coroa e medida com o auxílio de 
uma régua endodôntica. Deste valor obteve-se a odontometria, subtraindo-se 1 mm para determinação do comprimento real de trabalho.

Foi realizada a padronização do diâmetro do forame apical com a introdução do instrumento tipo K ํำ15, da marca Maillefer - Dentsply, até que este instrumento ficasse "travado" na posição de $1 \mathrm{~mm}$ além do forame apical e, em seguida, realizada a movimentação de $1 / 2$ volta no sentido horário e posterior retirada do instrumento. Convém salientar que os espécimes em que o instrumento de numeração 15 não permaneceu "travado" na posição de $1 \mathrm{~mm}$ além do forame apical, ou seja, espécimes com forame apical de diâmetros superiores a $0,17 \mathrm{~mm}$, foram descartados e substituídos.

A seguir, cada espécime ficou posicionado em morsa de apreensão entre duas lâminas de borracha. Nesta posição, foi realizado o preparo químicomecânico coroa-ápice e ápice-coroa, com instrumentos rotatórios série ProFile, marca Maillefer - Dentsply, com o auxílio de motor de redução 16:1, da marca Driller modelo Endo Pro e contra-ângulo 1:1 na velocidade de 350 rpm, utilizando, como substância química auxiliar, $15 \mathrm{ml}$ de hipoclorito de sódio a 0,5 \% associado ao creme de Endo-PTC, segundo técnica de Paiva e Antoniazzi (1993).

O preparo coroa-ápice consistiu da utilização dos instrumentos em posição aquém do comprimento real de trabalho, na seguinte seqüência de conicidades e diâmetros, respectivamente: ProFile Orifice Shaper $3(.06 / 40)$, ProFile Orifice Shaper 2 (.06/30), ProFile .06/25, ProFile .06/20, ProFile .04/25 e ProFile .04/20.

Em seguida, realizou-se o preparo ápice-coroa, que consistiu da utilização dos instrumentos ProFile no comprimento real de trabalho na conicidade .04 com a seguinte seqüência de diâmetros: 15, 20, 25, 30, 35, 40, 45 e 60. 
O preparo foi finalizado com a utilização manual do Verifier, marca Maillefer - Dentsply de diâmetro 60 , conicidade .04 , posicionado no limite do CRT, com movimentos rotatórios no sentido horário, certificando-se que o diâmetro nesta posição tivesse equivalência ao instrumento de ํㅜㅇ. 60 .

Findo o preparo, foram realizadas a irrigação e aspiração com cerca de 15 ml de EDTA-T a 17\%, aspiração do conteúdo com cânula metálica acoplada à bomba de vácuo e secagem final dos canais com cones de papel absorvente.

Após a remoção dos espécimes da morsa de apreensão, procedeurse à impermeabilização total da raiz, no sentido ápico-cervical com éster de cianoacrilato, da marca Super Bonder - Loctite, acorde Lage Marques (1992), procedimento este, auxiliado por um espaçador digital FF da marca Moyco - Union Broach, ultrapassando $1 \mathrm{~mm}$ o limite do forame apical.

Após a secagem do éster de cianoacrilato, foi confirmada a desobstrução do canal radicular, novamente com o instrumento Verifier da marca Maillefer Dentsply de diâmetro 60 , conicidade .04 , posicionado no limite do CRT, seguido da utilização do instrumento tipo K de numeração 10, marca Maillefer - Dentsply, até que sua ponta fosse visualizada em $1 \mathrm{~mm}$ além do forame, bem como, do espaçador digital FF da marca Moyco - Union Broach na mesma posição, no intuito de garantir a efetiva desobstrução do canal radicular no milímetro apical entre o CRT e o forame apical.

Em seguida, foi realizado o travamento do cone principal de obturação no CRT, com a utilização de um cone de guta-percha estandardizado de conicidade .04 , calibrado em régua calibradora no orifício de diâmetro 60 , ambos da marca Maillefer - Dentsply, e removido do canal radicular aguardando o momento da obturação. 
A seguir, cada raiz foi recoberta com filme transparente de PVC, marca Majipack, sendo esta película posicionada no sentido de apical para cervical e fixada com elástico ortodôntico de separação dental da marca Morelli no 1/3 médio da raiz, sendo removido, com tesoura, o excesso deste filme de PVC na região cervical da raiz.

Os dentes assim preparados foram distribuídos em quatro grupos experimentais de 15 espécimes cada, segundo as respectivas técnicas de obturação termoplastificada, além de dois grupos controle, positivo e negativo, contendo 2 espécimes, cujos dentes do grupo controle negativo foram reutilizados no grupo controle positivo.

Deste modo, os espécimes foram posicionados em um sistema de mensuração do volume de material obturador extruído, desenvolvido pelo Laboratório de Metrologia Volumétrica FGG, credenciado pelo INMETRO, conforme Certificado de Calibração nº 1890/2003 (contido nos ANEXOS), fixado em estrutura de madeira, ferro e aço inoxidável e constituído por um sistema de vasos comunicantes no formato da letra "J", contendo água destilada no seu interior, representado por um tubo de vidro para posicionamento de cada espécime no lado esquerdo, que se comunica com um capilar de vidro de $0,35 \mathrm{~mm}$ de diâmetro no lado direito, constituindo uma escala graduada, com volume total de 20 microlitros $(\mu l)$ e subdivisões de 0,2 microlitros $(\mu l)$ para mensuração do deslocamento de volume (Figuras 4.2.1 a 4.2.4). 


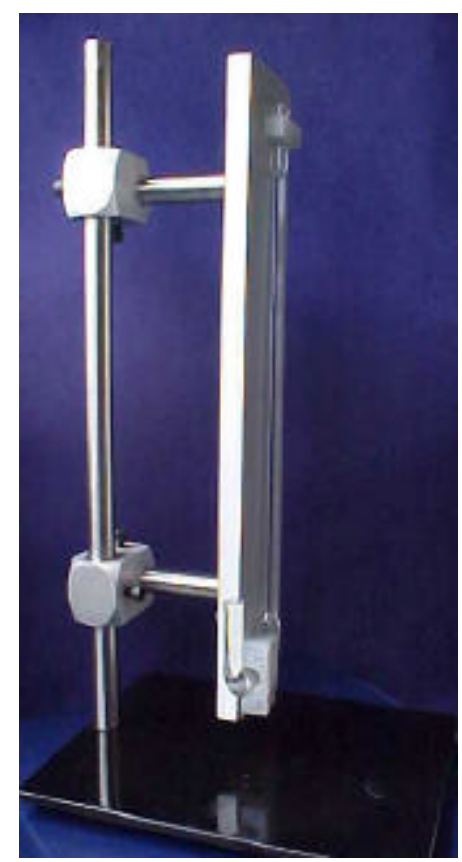

Figura 4.2.1 - Sistema de mensuração (vista lateral)

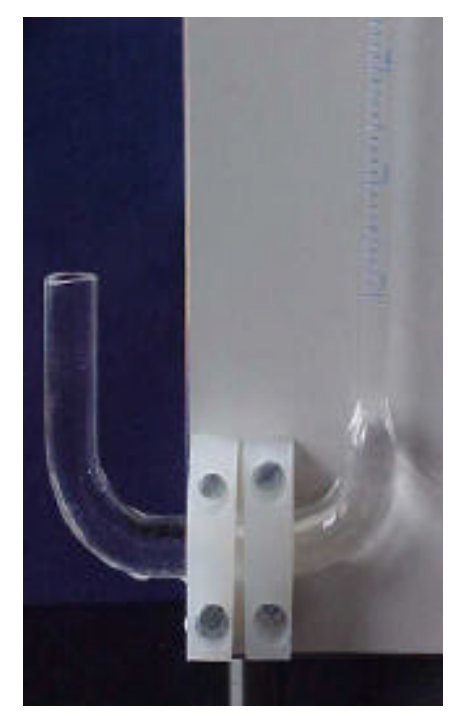

Figura 4.2.3 - Vasos comunicantes

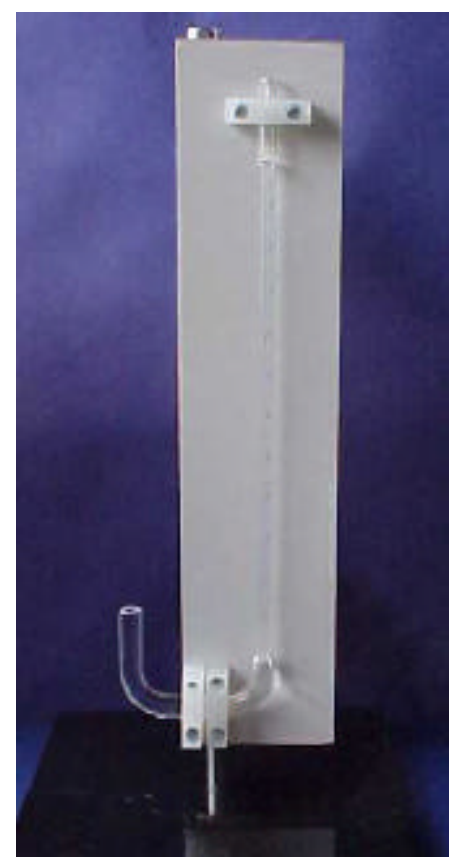

Figura 4.2.2 - Sistema de mensuração (vista frontal)

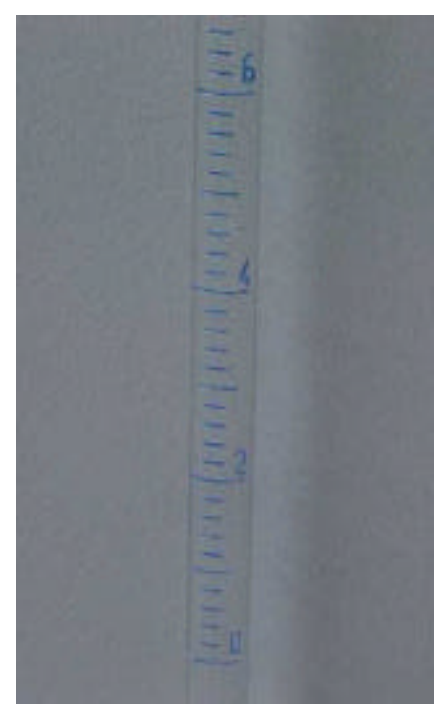

Figura 4.2.4 - Escala graduada 
Convém aclarar que, previamente ao posicionamento do dente, foi colocada água destilada no interior do sistema de mensuração, bem como, aplicação de vaselina líquida na extremidade externa do tubo de vidro no lado esquerdo do sistema. Em seguida, o 1/3 médio e cervical da raiz foi recoberto com resina acrílica quimicamente ativada e o dente posicionado nesta extremidade do tubo anteriormente vaselinada. A seguir, camadas adicionais de resina quimicamente ativada foram inseridas ao redor do dente e do tubo de vidro, no intuito de impedir a movimentação do espécime durante a fase de obturação do canal radicular (Figura 4.2.5).

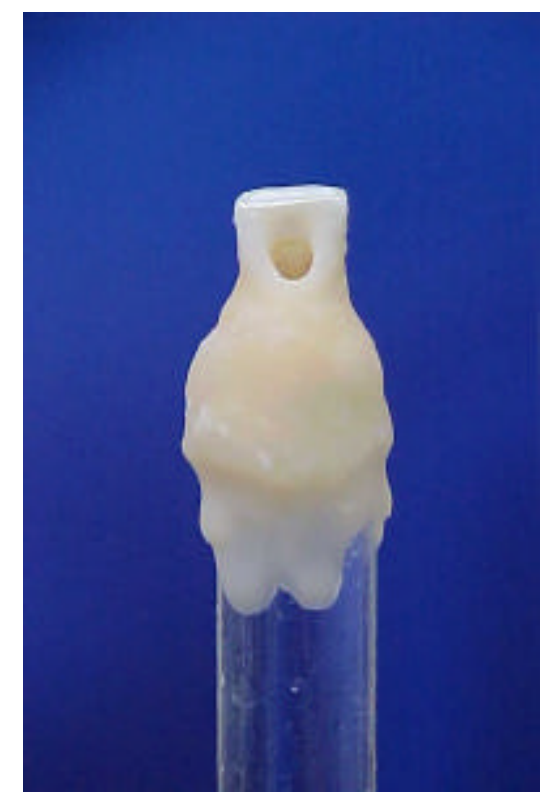

Figura 4.2.5 - Dente posicionado no sistema de mensuração de volume 
Após o tempo de presa da resina quimicamente ativada, o volume de cada dente foi mensurado na escala graduada, previamente à obturação do canal radicular e anotado em tabela específica.

Neste momento, foi novamente inserido um cone de papel absorvente no canal radicular até a posição do comprimento real de trabalho, no intuito de confirmar que não ocorreu a penetração do líquido do sistema para o interior do canal através do forame apical.

Os dentes do primeiro grupo, denominado $\mathrm{G} 1$, foram obturados com a técnica Thermafil, revestindo inicialmente as paredes do canal com cimento, através do cone principal de guta-percha calibrado e anteriormente travado. Em seguida, foi inserido no canal até o CRT, o carregador plástico de diâmetro 60, previamente escolhido, mensurado e termoplastificado no forno Thermaprep Plus a $115{ }^{\circ} \mathrm{C}$ por 30 segundos aproximadamente (Figura 4.2.6), seguido de condensação vertical.

Os dentes do segundo grupo, denominado G2, foram obturados com gutapercha termoplastificada a alta temperatura Sistema Obtura II, revestindo inicialmente as paredes do canal com cimento através do cone principal de gutapercha calibrado e anteriormente travado. Em seguida, foi injetada no canal radicular, com a cânula posicionada a $3 \mathrm{~mm}$ aquém do CRT, a guta percha em bastão previamente inserida e termoplastificada na pistola, acoplada ao aquecedor específico Obtura II a $200{ }^{\circ} \mathrm{C}$ por 1,5 minutos aproximadamente (Figura 4.2.7), seguido de condensação vertical. 


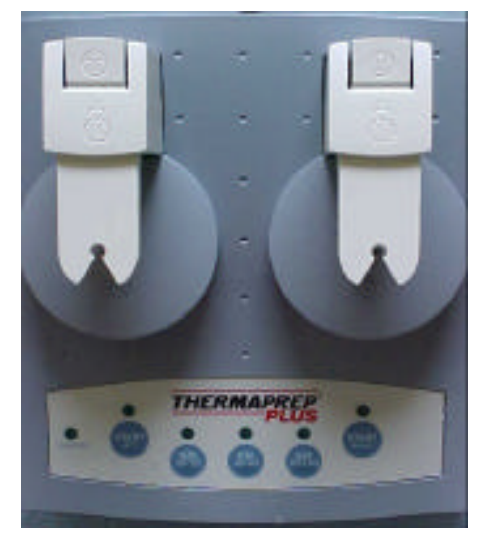

Figura 4.2.6 - Forno Thermaprep Plus

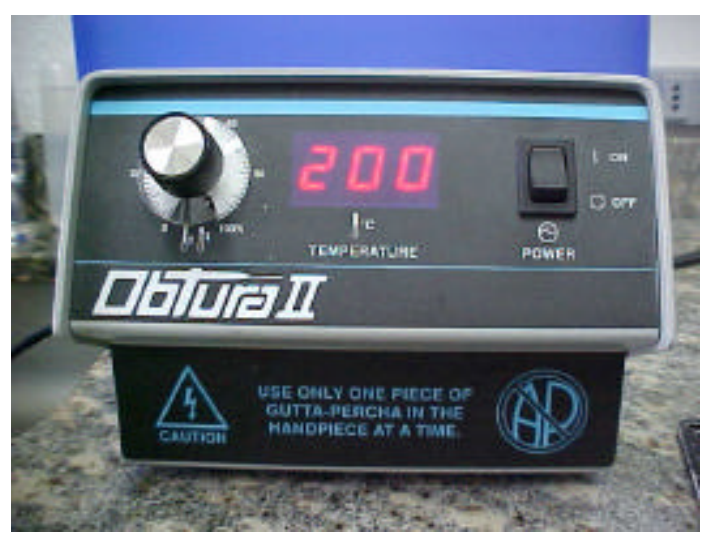

Figura 4.2.7 - Aquecedor Obtura II

Os dentes do terceiro grupo, denominado G3, foram obturados com gutapercha termoplastificada a baixa temperatura Sistema Ultrafil 3D, revestindo inicialmente as paredes do canal com cimento através do cone principal de gutapercha calibrado e anteriormente travado. Em seguida, foi injetada no canal radicular através de pistola específica, a guta-percha FirmSet, acoplada em cânula e posicionada a $3 \mathrm{~mm}$ aquém do $\mathrm{CRT}$, previamente termoplastificada em aquecedor específico Hygenic a $70{ }^{\circ} \mathrm{C}$ por 15 minutos aproximadamente (Figura 4.2.8), seguido de condensação vertical.

Os dentes do quarto grupo, denominado G4, foram obturados pela técnica Fusionada (MOURA; OTANI; DAVIDOWICZ, 1999/2000), revestindo inicialmente as paredes do canal com cimento através do cone principal de guta-percha calibrado e anteriormente travado. A seguir, este cone mestre foi recoberto com guta-percha termoplastificada a baixa temperatura FirmSet - Sistema Ultrafil 3D, iniciando-se na porção mais calibrosa e terminando na porção apical do cone, sendo neste momento novamente introduzido no canal radicular até o CRT, seguido de condensação vertical (Figura 4.2.9). 




Figura 4.2.8 - Aquecedor Hygenic

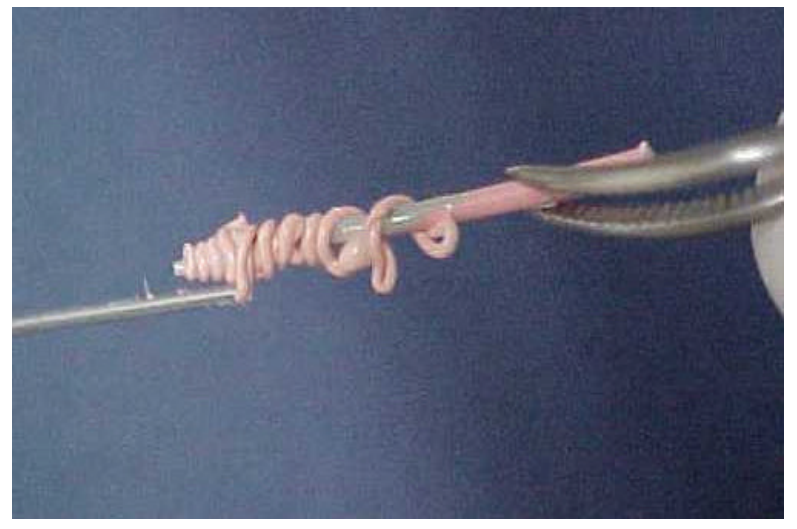

Figura 4.2.9 - Técnica Fusionada

Convém salientar que o cimento obturador utilizado em todos os grupos experimentais foi o $\mathrm{N}$-Rickert, revestindo as paredes do canal com duas aplicações sucessivas de pequenas porções de cimento na ponta do cone principal de guta-percha calibrado e anteriormente travado, inserido até a posição de $2 \mathrm{~mm}$ aquém do CRT.

Após terminada a obturação, foi realizada novamente a leitura do volume através da escala graduada e o respectivo valor anotado na tabela apropriada.

A diferença entre o volume de cada espécime, antes e após a obturação do canal radicular, indicou o volume de material obturador extruído em microlitros.

Os espécimes do grupo controle negativo, denominado GCN, não foram obturados, no entanto, em cada dente foi introduzido, sem cimento, o cone principal de guta-percha calibrado e anteriormente travado, até o CRT, realizada a leitura do volume no sistema de mensuração e anotado em tabela específica. 
Após esta mensuração e a retirada do cone principal anteriormente travado, estes mesmos espécimes do grupo controle negativo (GCN) foram utilizados no grupo controle positivo, denominado GCP, que também não foram obturados. No entanto, em cada dente foi introduzido, sem cimento, outro cone principal de gutapercha estandardizado, conicidade .02, de numeração 15, marca Dentsply Maillefer, ultrapassando intencionalmente o forame apical até o travamento do mesmo na posição além forame, realizada a leitura do volume no sistema de mensuração e anotado em tabela específica.

Com os resultados das diferenças quantitativas de volumes assim obtidos, realizou-se a tabulação dos grupos experimentais e controle.

Após a remoção dos espécimes do sistema de mensuração, os dentes foram analisados qualitativamente através da inspeção visual, com o auxílio de lupa de 10 aumentos, em relação à freqüência da extrusão apical de material obturador classificando-os em: sem extrusão e extrusões de cimento; guta-percha; cimento e guta-percha.

Com os resultados da análise qualitativa das freqüências de extrusão visual assim obtidos, procedeurse à tabulação dos grupos experimentais.

A seguir, os dentes foram radiografados nos sentidos vestíbulo-lingual e mésio-distal, através da técnica periapical do paralelismo, posicionando-os nas películas radiográficas com auxílio de cera utilidade, na distância focal de $2,5 \mathrm{~cm}$, tempo de exposição de 0,4 segundos, sendo as radiografias processadas com tempo de revelação e fixação em 25 segundos e 20 minutos, respectivamente. 
Após lavagem e tempo de secagem, as radiografias dos grupos experimentais foram avaliadas nos terços médio e apical, por 2 examinadores experientes, Doutores em Endodontia, com o auxílio de negatoscópio, em relação à qualidade final da obturação, baseados no critério da Tabela 4.2.1. proposto por Kytridou, Gutmann e Nunn (1999).

Tabela 4.2.1 - Critério de Avaliação Radiográfica

\begin{tabular}{|c|c|}
\hline Escore & Critério \\
\hline 0 & $\begin{array}{l}\text { Obturação densa, radiopaca com boa } \\
\text { adaptação de guta-percha no contorno do } \\
\text { canal } \\
\text { Presença de pequenas lacunas ou bolhas } \\
(<0,5 m m) \text { no } 1 / 3 \text { apical e/ou na totalidade da } \\
\text { obturação }\end{array}$ \\
\hline 2 & $\begin{array}{l}\text { Presença de lacunas ou bolhas } \\
(>0,5 \mathrm{~mm}<1,0 \mathrm{~mm}) \text { no } 1 / 3 \text { apical e/ou na } \\
\text { totalidade da obturação }\end{array}$ \\
\hline 3 & $\begin{array}{l}\text { Presença de lacunas ou bolhas } \\
(>1,0 \mathrm{~mm}<2,0 \mathrm{~mm}) \text { no } 1 / 3 \text { apical e/ou na } \\
\text { totalidade da obturação }\end{array}$ \\
\hline 4 & $\begin{array}{l}\text { Presença de lacunas ou bolhas (> 2,0mm) no } \\
1 / 3 \text { apical e/ou na totalidade da obturação }\end{array}$ \\
\hline
\end{tabular}

Com os resultados da avaliação da qualidade radiográfica final das obturações termoplastificadas realizourse a tabulação dos grupos experimentais.

Convém salientar que todos os procedimentos descritos nos MÉTODOS, exceto as avaliações radiográficas, foram realizados pelo mesmo operador em temperatura ambiente controlada de $20^{\circ} \mathrm{C}$, aproximadamente. 
Em seguida, de posse dos dados tabulados, procedeu-se à análise estatística quantitativa e qualitativa dos resultados, adotando o nível de significância de $5 \%(p<0,05)$ para todos os testes. 


\title{
Faculdade de Odontologia
}

\author{
Universidade de São Paulo
}

PARECER $n^{\circ} 141 / 03$

Protocolo 144/03

O Grupo de trabalho indicado pelo Comitê de Ética em Pesquisa, APROVOU o protocolo de pesquisa "Avaliação quantitativa da extrusăo apical em técnicas de obturação termoplastificada" de responsabilidade do pesquisador Fábio Strefezza, sob orientação do Professor Doutor Abilio A. Maranhão de Moura.

Tendo em vista a legislaçăo vigente, devem ser encaminhados a este Comitê relatórios referentes ao andamento da pesquisa em 27 de fevereiro de 2004 e em 27 de agosto de 2004. Ao término da pesquisa, cópia do trabalho em "cd" ou "disquete", deve ser encaminhada a este CEP.

São Paulo, 28 de agosto de 2003.

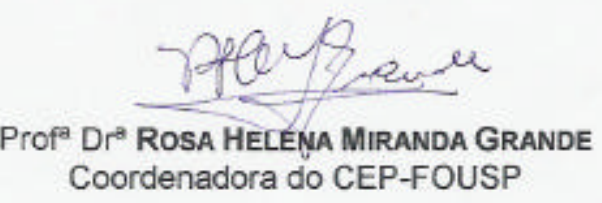

Av, Prof. Lineu Prestes, 2227 - Cidade Universitária "Armando de Salles Oliveira" CEP 05508-900 Săo Paulo - SP Diretoria Telefax (011) 38140062 - $30917817 / 60$ 
5 RESULTADOS 


\section{RESULTADOS}

Nas Tabelas Ap.1 a Ap.6, podemos encontrar os valores quantitativos de volume, expressos em $\mu \mathrm{l}$, mensurados na escala graduada do sistema de mensuração, antes e após a obturação do canal radicular, bem como, a diferença entre as duas mensurações, indicando o volume de material obturador extruído nos grupos experimentais e controles.

As espécimes $n^{\circ} 4$ do grupo G3 (Ultrafil 3D) e o13 do grupo G2 (Obtura II) apresentaram maior e menor volumes de material extruído com $11,8 \mu \mathrm{l}$ e $1,4 \mu \mathrm{l}$, respectivamente (Tabelas Ap.3 e Ap.2).

Nas Tabelas Ap.5 e Ap.6, constatamos que não houve variação de volume no grupo controle negativo (GCN), enquanto que no grupo controle positivo (GCP) confirmou-se a variação de volume.

Em todas as técnicas de guta-percha termoplastificada dos grupos experimentais houve extrusão de material obturador, como podemos verificar na Tabela Ap.7, cujas médias de volume de material extruído estão expressas na Tabela 5.1 e representadas no Gráfico da Figura 5.1. 
Tabela 5.1 - Médias de volume de material obturador extruído dos grupos experimentais, expressos em $\mu$ l.

\begin{tabular}{cccc}
\hline $\begin{array}{c}\text { Thermafil } \\
\text { (G1) }\end{array}$ & $\begin{array}{c}\text { Obtura II } \\
\text { (G2) }\end{array}$ & $\begin{array}{c}\text { Ultrafil 3D } \\
\text { (G3) }\end{array}$ & $\begin{array}{c}\text { Fusionada } \\
\text { (G4) }\end{array}$ \\
\hline 6,3 & 5,0 & 5,3 & 6,3 \\
\hline
\end{tabular}

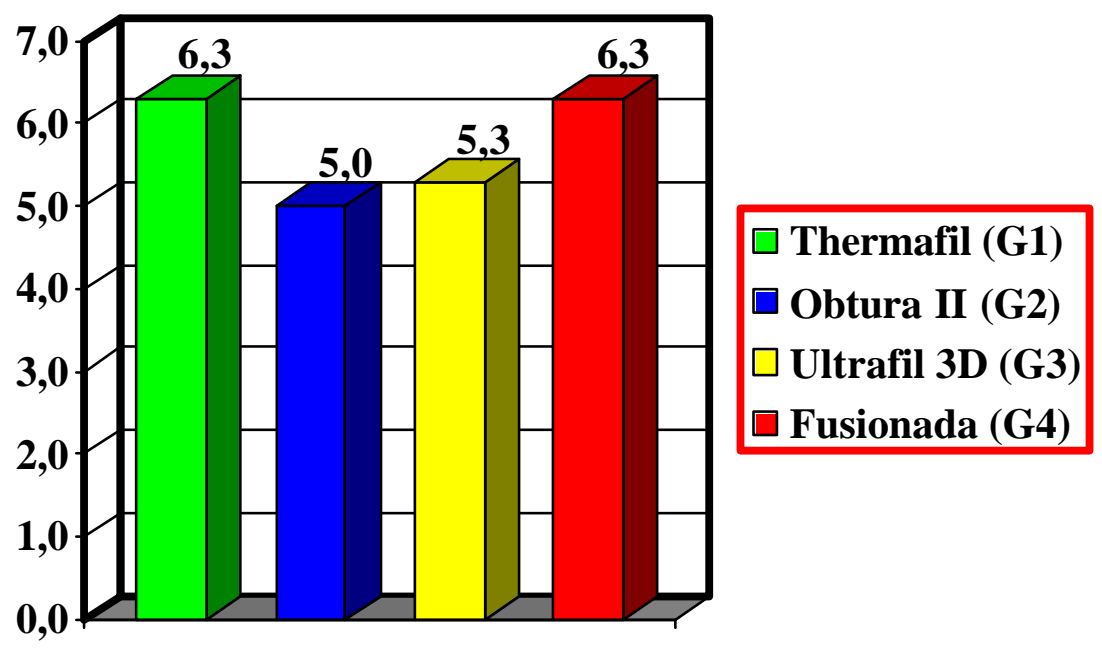

Figura 5.1 - Médias de volume de material obturador extruído dos grupos experimentais, expressos em $\mu$ l.

A seguir, os valores dos volumes de material obturador extruído dos grupos experimentais foram submetidos ao Teste de Aderência à Curva Normal, sendo constatada distribuição amostral testada normal, conforme Tabela Ap.8. 
Desta forma, os grupos experimentais foram avaliados através do teste estatístico de Análise de Variância (ANOVA), no nível de significância de 5\% $(p<0,05)$, para identificarmos possíveis diferenças quantitativas entre os quatro grupos considerados, para as médias aritméticas do volume. Os resultados revelaram ausência de diferença estatisticamente significante entre as médias de volume $(p=0,234)$, conforme Tabela 5.2.

\footnotetext{
Tabela 5.2 -Teste de Análise de Variância (ANOVA) das médias dos volumes de material obturador extruído dos grupos experimentais.
}

\begin{tabular}{c|c|c|c|c|c}
\hline Fonte de variação & $\begin{array}{c}\text { Soma de } \\
\text { Quadrados }\end{array}$ & G.L. & $\begin{array}{c}\text { Quadrados } \\
\text { Médios }\end{array}$ & (F) & (p) \\
\hline Entre grupos & 21,431 & 3 & 7,144 & 1,465 & 0,234 \\
Resíduo & 273,003 & 56 & 4,875 & & \\
Total & 294,434 & 59 & & \\
\hline
\end{tabular}

$\mathrm{Na}$ análise qualitativa da extrusão visual de material obturador, as classificações de sem extrusão e extrusões de cimento; guta-percha; cimento e guta-percha, foram identificados pelos valores $0,1,2$ e 3, respectivamente, para realização da análise estatística.

Na Tabela Ap.9, podemos encontrar as freqüências da extrusão visual de guta-percha e/ou cimento nos grupos experimentais, identificados individualmente, enquanto que na Tabela 5.3, está representado o resumo das somatórias das freqüências com as respectivas percentagens.

Em todos os espécimes em que ocorreram extrusões de guta-percha, consta tou-se que as mesmas foram acompanhadas de extrusões de cimento. 
Analisando as somas das freqüências da extrusão visual de guta-percha e/ou cimento (Tabela 5.3), verificou-se que houve extrusão de guta-percha com cimento nos grupos Thermafil (G1), Ultrafil 3D (G3) e Fusionada (G4), enquanto que no grupo Obtura II (G2) ocorreu somente extrusão de cimento.

Tabela 5.3 - Somas das freqüências da extrusão visual com as respectivas percentagens.

\begin{tabular}{c|c|c|c|c}
\hline $\begin{array}{c}\text { Extrusão } \\
\text { visual }\end{array}$ & $\begin{array}{c}\text { Thermafil } \\
(\mathbf{G 1})\end{array}$ & $\begin{array}{c}\text { Obtura II } \\
(\mathbf{G 2})\end{array}$ & $\begin{array}{c}\text { Ultrafil 3D } \\
\text { (G3) }\end{array}$ & $\begin{array}{c}\text { Fusionada } \\
\text { (G4) }\end{array}$ \\
\hline Sem Extrusão (0) & $0(0 \%)$ & $0(0 \%)$ & $0(0 \%)$ & $0(0 \%)$ \\
Cimento (1) & $3(20 \%)$ & $15(100 \%)$ & $0(0 \%)$ & $8(53 \%)$ \\
$\begin{array}{c}\text { Guta-percha (2) } \\
\text { Cimento e }\end{array}$ & $0(0 \%)$ & $0(0 \%)$ & $0(0 \%)$ & $0(0 \%)$ \\
Guta-percha (3) & $12(80 \%)$ & $0(0 \%)$ & $15(100 \%)$ & $7(47 \%)$ \\
\hline Total & $15(100 \%)$ & $15(100 \%)$ & $15(100 \%)$ & $15(100 \%)$ \\
\hline
\end{tabular}

Desta forma, os grupos G1 (Thermafil) e G4 (Fusionada) foram avaliados individualmente através do teste $\mathrm{t}$ de Student, para identificarmos possíveis diferenças entre as médias das proporções de extrusão visual de cimento e gutapercha em comparação com cimento dentro de cada grupo, constatando que houve diferença altamente significativa no grupo $G 1(p<0,001)$, enquanto que não houve diferença estatisticamente significante no grupo $G 4(p=0,726)$, conforme Tabela Ap.10.

$\mathrm{Na}$ análise qualitativa entre os quatro grupos experimentais, frente às freqüências de extrusão visual (sem extrusão e extrusões de cimento; gutapercha; cimento e guta-percha), foi aplicado o Teste de Kruskal-Wallis, 
identificando diferenças altamente significativas entre os grupos $(p<0,001)$, conforme Tabela Ap.11.

Logo após, tais resultados foram avaliados pelo Teste de Mann-Whitney, para identificarmos possíveis diferenças entre os pares de grupos considerados, constatando que houve diferenças estatisticamente significantes entre grupos G1 Thermafil e G2-Obtura II ( $p<0,001)$, G2-Obtura II e G3-Ultrafil 3D ( $p<0,001)$, G2Obtura II e G4-Fusionada ( $p=0,029)$, G3-Ultrafil 3D e G4-Fusionada ( $p=0,011$ ), porém, apesar das diferenças em percentagem, não ocorreram diferenças estatisticamente significantes entre os grupos G1-Thermafil e G3-Ultrafil 3D ( $p=0,367)$, G1-Thermafil e G4-Fusionada $(p=0,126)$, indicando semelhança na extrusão visual nestas comparações (Tabela 5.4).

Tabela 5.4 - Teste de Mann-Whitney das freqüências da extrusão visual entre os pares dos grupos experimentais.

\begin{tabular}{l|l|l|l|l|l|l}
\hline Grupos & G1 X G2 & G1 X G3 & G1 X G4 & G2 X G3 & G2 X G4 & G3 X G4 \\
Sig. & $<0,001 \quad 0,367$ & 0,126 & $<0,001$ & 0,029 & 0,011 \\
\hline$p$ & & & & \\
\hline $\begin{array}{l}\text { G1 } \\
\text { G2 }=\text { Thermafil }\end{array}$ \\
G3 = Ubtura II \\
G4 $=$ Fusionada
\end{tabular}

Em relação à análise radiográfica final das obturações termoplastificadas, nas Tabelas Ap.12 e Ap.13, podemos encontrar as freqüências dos escores das avaliações radiográficas realizadas por cada examinador, conforme critério descrito nos MÉTODOS, identificados individualmente nos sentidos vestíbulolingual e mésio-distal, enquanto que na Tabela 5.5, está representado o resumo 
das somatórias das freqüências dos dois examinadores em ambos os sentidos de observação.

Tabela 5.5 - Somas das freqüências dos escores, da avaliação radiográfica final da obturação nos grupos experimentais dos dois examinadores.

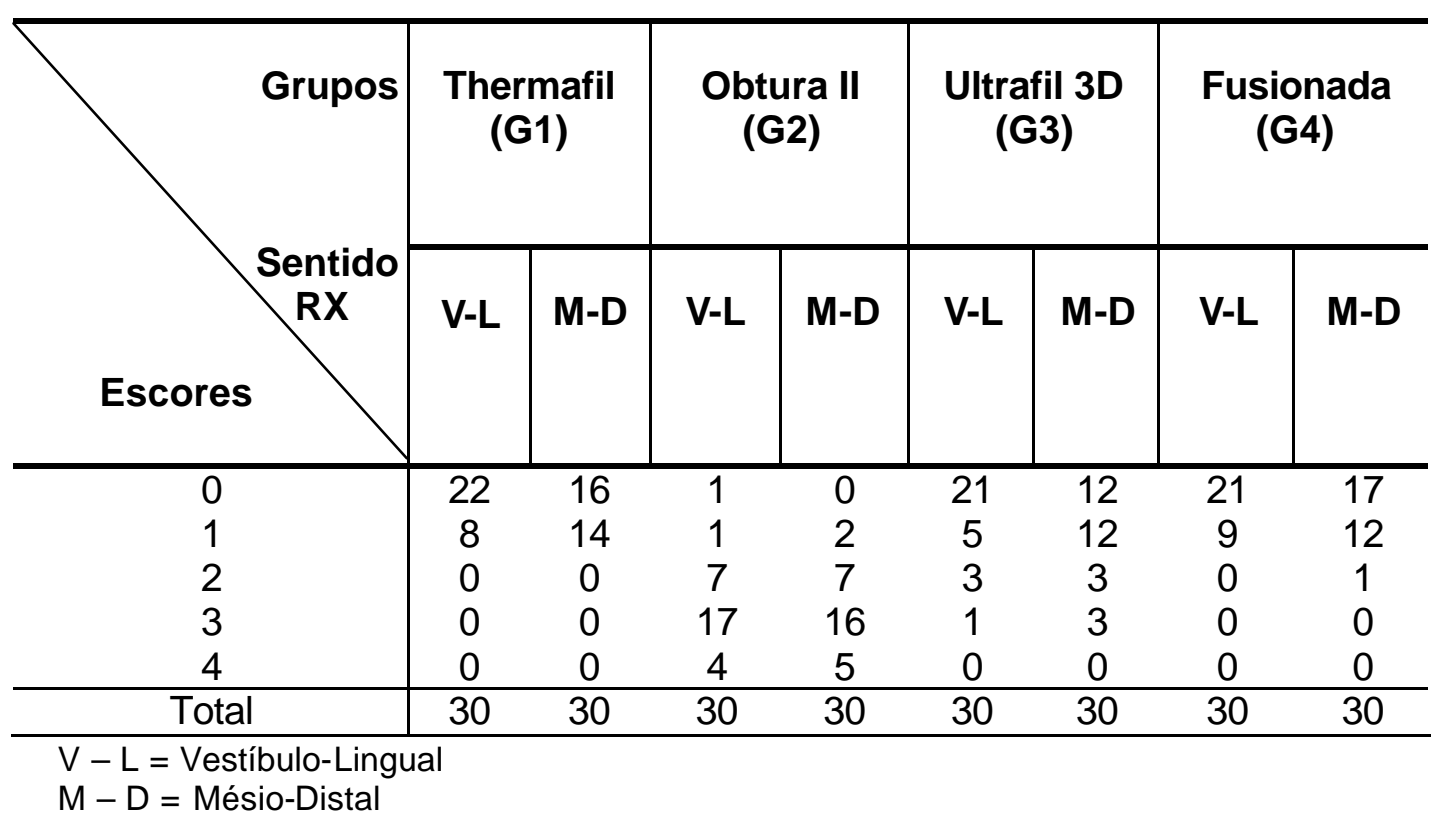

Nesta análise qualitativa, primeiramente os dois examinadores foram avaliados pelo Teste dos Postos Sinalizados de Wilcoxon, para identificarmos possíveis diferenças nas interpretações radiográficas para cada grupo experimental, nos dois sentidos vestíbulo-lingual e mésio-distal, constatando que houve concordância na maioria das avaliações radiográficas, indicando semelhança entre os dois examinadores (Tabela Ap.14).

Os resultados das análises radiográficas das obturações, representados em resumo na Tabela 5.5, foram avaliados pelo Teste de Kruskal-Wallis, para identificarmos possíveis diferenças entre os grupos experimentais nos dois 
sentidos de avaliação separadamente, constatando-se diferenças altamente significativas em ambos os sentidos ( $p<0,001)$, conforme Tabela Ap.15.

Logo após, foi aplicado o Teste de Mann-Whitney, para identificarmos possíveis diferenças entre os pares de grupos, constatando-se diferenças estatisticamente significantes, em ambos os sentidos, na comparação do grupo G2 (Obtura II) com todos os outros grupos experimentais, bem como, ausência de diferenças significativas entre os grupos G1 (Thermafil), G3 (Ultrafil 3D) e G4 (Fusionada) entre si (Tabela 5.6).

Tabela 5.6 - Teste de Mann-Whitney das avaliações radiográficas entre os pares dos grupos experimentais, nos sentidos vestíbulo-lingual e mésio-distal.

\begin{tabular}{c|c|c}
\hline Sentido-RX & Grupos & Sig. (p) \\
\hline Vestíbulo-Lingual & G1 X G2 & $<0,001$ \\
& G1 X G3 & 0,838 \\
& G1 X G4 & 0,902 \\
& G2 X G3 & $<0,001$ \\
& G2 X G4 & $<0,001$ \\
& G3 X G4 & 0,902 \\
\hline Mésio-Distal & G1 X G2 & $<0,001$ \\
& G1 X G3 & 0,285 \\
& G1 X G4 & 1,000 \\
& G2 X G3 & $<0,001$ \\
& G2 X G4 & $<0,001$ \\
& G3 X G4 & 0,285 \\
\hline
\end{tabular}

G1 = Thermafil

G2 = Obtura II

G3 = Ultrafil 3D

G4 = Fusionada

A seguir, foi aplicado o teste de Análise de Variância (ANOVA), para identificarmos possíveis diferenças entre os quatro grupos considerados, nas proporções de interpretações radiográficas nos escores $0,1,2,3$ e 4, 
constatando-se diferenças altamente significativas entre os grupos (Tabela Ap.16).

Posteriormente, tais resultados foram avaliados pelo Teste de Dunnet, para identificarmos possíveis diferenças entre os pares de grupos para cada escore, no respectivo sentido de avaliação radiográfica, constatando-se que o Obtura II (G2) foi o único grupo que apresentou o escore 4 nas avaliações vestíbulo-lingual e mésio-distal com os dois examinadores (Tabela 5.5), bem como, diferenças significativas com todos os outros grupos nos escores 0 e 3 nos dois sentidos de avaliação e escore 1 no sentido mésio-distal (Tabela 5.7).

Finalizando esta análise qualitativa, foi aplicado o Teste dos Postos Sinalizados de Wilcoxon, para identificarmos possíveis diferenças entre os dois sentidos de avaliação radiográfica, vestíbulo-lingual e mésio-distal em cada grupo experimental, constatando-se diferenças significativas no grupo G3-Ultrafil 3D $(p=0,013)$, enquanto que nos demais grupos não houve diferenças estatisticamente significantes (Tabela Ap.17).

Nas Figuras 5.2 a 5.9, foram escolhidos, a título de ilustração, os resultados visuais e radiográficos nos sentidos vestíbulo-lingual e mésio-distal de dois espécimes de cada grupo experimental com maiores e menores valores de extrusão quantitativa de volume, respectivamente, bem como, nas Figuras 5.10 e 5.11, os resultados do grupo controle positivo (GCP). 
Tabela 5.7 - Teste de Dunnet das avaliações radiográficas entre os pares dos grupos experimentais para cada escore, nos sentidos vestíbulo-lingual e mésio-distal.

\begin{tabular}{|c|c|c|c|}
\hline Escores & Grupos & $\begin{array}{c}\text { Sig. (p) } \\
V-L\end{array}$ & $\begin{array}{c}\text { Sig. (p) } \\
M-D\end{array}$ \\
\hline 0 & $\begin{array}{l}\mathrm{G} 1 \times \mathrm{G} 2 \\
\mathrm{G} 1 \times \mathrm{G} 3 \\
\mathrm{G} 1 \times \mathrm{G} 4 \\
\mathrm{G} 2 \times \mathrm{G} 3 \\
\mathrm{G} 2 \times \mathrm{G} 4 \\
\mathrm{G} 3 \times \mathrm{G} 4\end{array}$ & $\begin{array}{c}<0,001 \\
1,000 \\
1,000 \\
<0,001 \\
<0,001 \\
1,000\end{array}$ & $\begin{array}{c}<0,001 \\
0,884 \\
1,000 \\
0,001 \\
<0,001 \\
0,733\end{array}$ \\
\hline 1 & $\begin{array}{l}\mathrm{G} 1 \times \mathrm{G} 2 \\
\mathrm{G} 1 \times \mathrm{G} 3 \\
\mathrm{G} 1 \times \mathrm{G} 4 \\
\mathrm{G} 2 \times \mathrm{G} 3 \\
\mathrm{G} 2 \times \mathrm{G} 4 \\
\mathrm{G} 3 \times \mathrm{G} 4\end{array}$ & $\begin{array}{l}0,069 \\
0,923 \\
1,000 \\
0,419 \\
0,034 \\
0,780 \\
\end{array}$ & $\begin{array}{l}0,002 \\
0,996 \\
0,996 \\
0,013 \\
0,013 \\
1,000 \\
\end{array}$ \\
\hline 2 & $\begin{array}{l}\mathrm{G} 1 \times \mathrm{G} 2 \\
\mathrm{G} 1 \times \mathrm{G} 3 \\
\mathrm{G} 1 \times \mathrm{G} 4 \\
\mathrm{G} 2 \times \mathrm{G} 3 \\
\mathrm{G} 2 \times \mathrm{G} 4 \\
\mathrm{G} 3 \times \mathrm{G} 4\end{array}$ & $\begin{array}{c}0,034 \\
0,389 \\
* \\
0,666 \\
0,034 \\
0,389\end{array}$ & $\begin{array}{l}0,034 \\
0,389 \\
0,893 \\
0,666 \\
0,133 \\
0,883\end{array}$ \\
\hline 3 & $\begin{array}{l}\text { G1 X G2 } \\
\text { G1 X G3 } \\
\text { G1 X G4 } \\
\text { G2 X G3 } \\
\text { G2 X G4 } \\
\text { G3 X G4 }\end{array}$ & $\begin{array}{c}<0,001 \\
0,893 \\
* \\
<0,001 \\
<0,001 \\
0,893\end{array}$ & $\begin{array}{c}<0,001 \\
0,389 \\
* \\
0,001 \\
<0,001 \\
0,389\end{array}$ \\
\hline 4 & $\begin{array}{l}\mathrm{G} 1 \times \mathrm{G} 2 \\
\mathrm{G} 1 \times \mathrm{G} 3 \\
\mathrm{G} 1 \times \mathrm{G} 4 \\
\mathrm{G} 2 \times \mathrm{G} 3 \\
\mathrm{G} 2 \times \mathrm{G} 4 \\
\mathrm{G} 3 \times \mathrm{G} 4\end{array}$ & $\begin{array}{c}0,224 \\
* \\
* \\
0,224 \\
0,224 \\
*\end{array}$ & $\begin{array}{c}0,124 \\
* \\
* \\
0,124 \\
0,124 \\
*\end{array}$ \\
\hline
\end{tabular}

$\mathrm{V}-\mathrm{L}=$ Vestíbulo-Lingual

$M-D=$ Mésio-Distal

G1 $=$ Thermafil

$\mathrm{G} 2=$ Obtura II

G3 $=$ Ultrafil 3D

G4 = Fusionada

* = Ausência do escore 


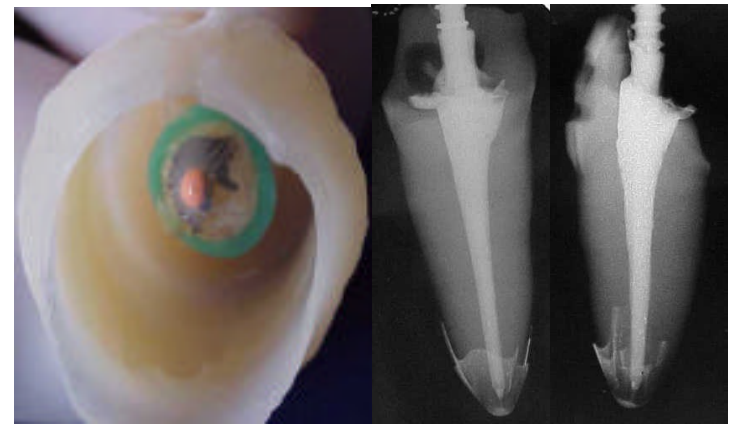

Figura 5.2 - Thermafil (G1) - espécime № 3

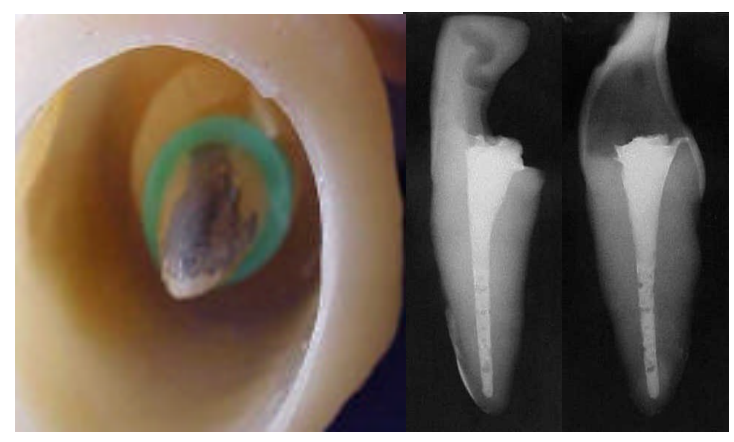

Figura 5.4 - Obtura II (G2) - espécime ํํ 5

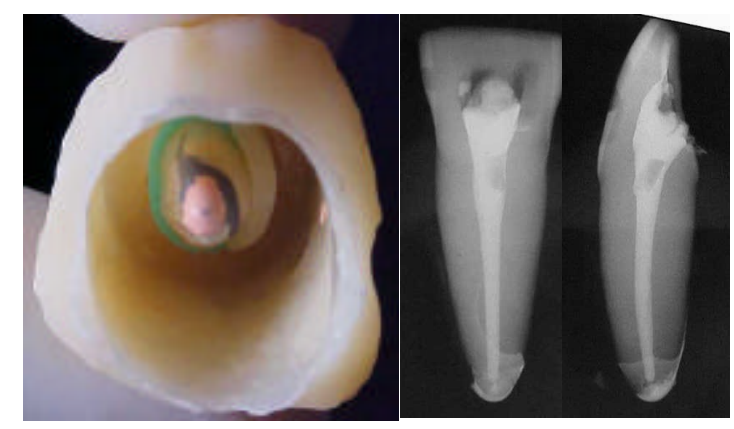

Figura 5.6 - Ultrafil 3D (G3) - espécime no 4

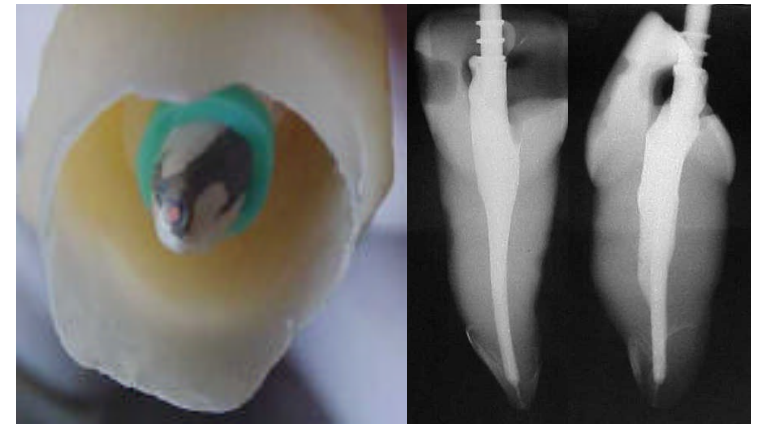

Figura 5.3 - Thermafil (G1) - espécime ํo 7

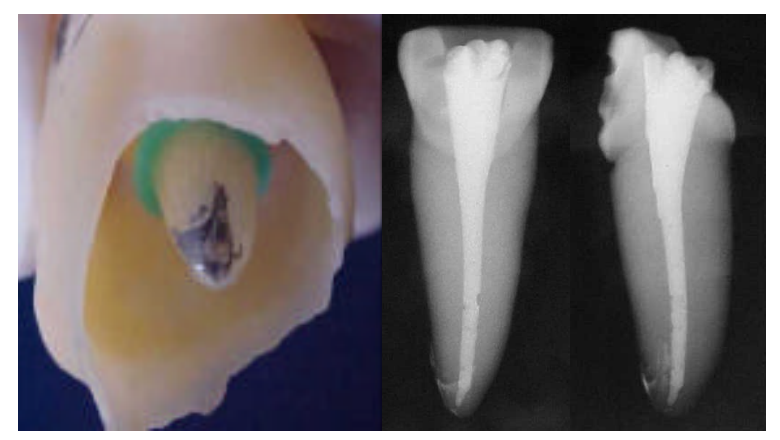

Figura 5.5 - Obtura II (G2) - espécime no 13

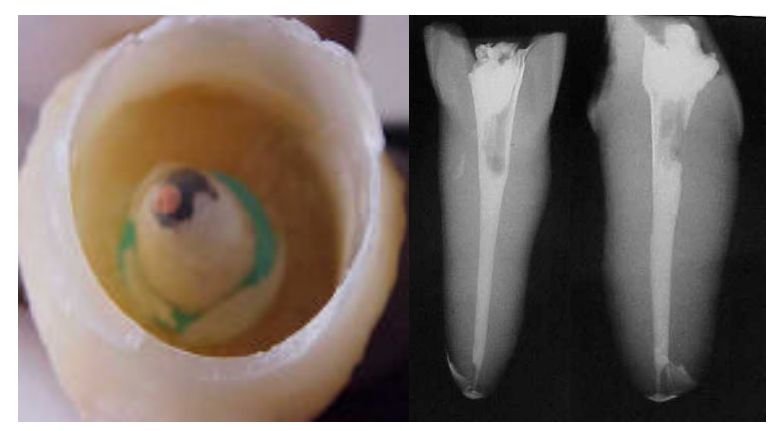

Figura 5.7 - Ultrafil 3D (G3) - espécime no 14 


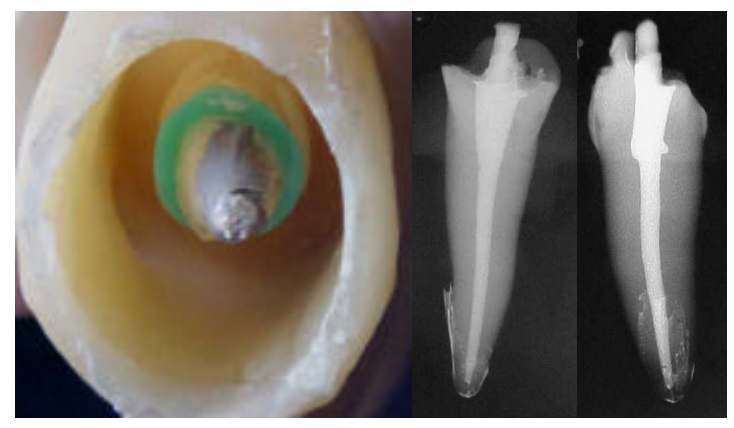

Figura 5.8 - Fusionada (G4) - espécime no 7

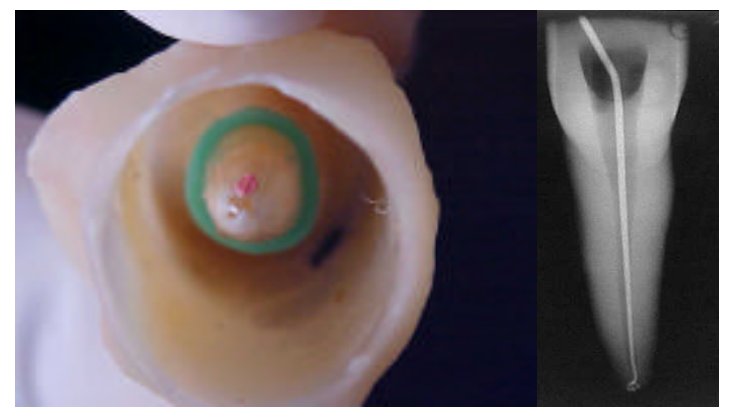

Figura 5.10 - Controle Positivo (GCP) espécime $n^{0} 1$

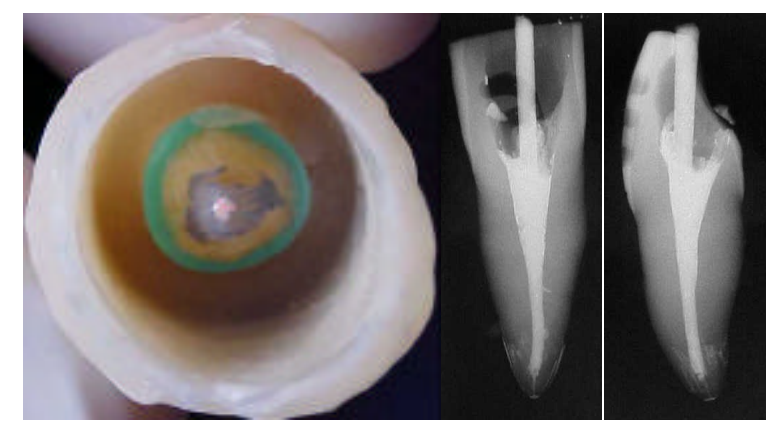

Figura 5.9 - Fusionada (G4) - espécime № 2

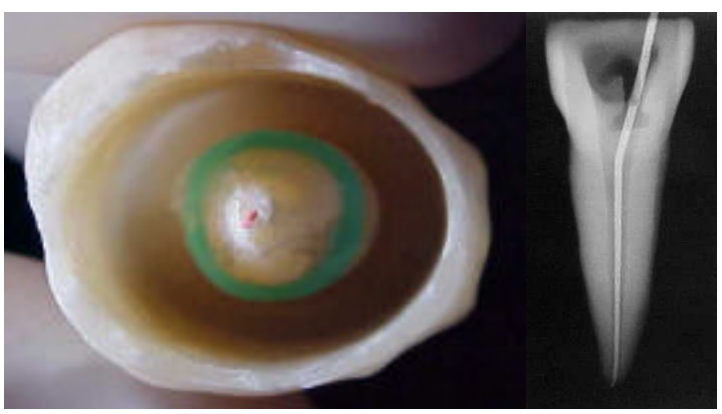

Figura 5.11 - Controle Positivo (GCP) espécime $\mathrm{n}^{\circ} 2$ 
6 DISCUSSÃo 


\section{DISCUSSÃO}

O sucesso de qualquer método de obturação, principalmente das técnicas de guta-percha termoplastificada, depende de um correto preparo do canal radicular, de forma cônica com constrição apical definida ou com o mínimo de abertura foraminal, para obter-se um efetivo selamento apical na utilização destas técnicas (OLSON; HARTWELL; WELLER, 1989; MOURA et al., 1989; MOURA, 1990; CLARK; ELDEEB, 1993; DUMMER et al., 1993; GUTMANN et al., 1993a, 1993b; DUMMER et al., 1994; LLOYD et al., 1995; GULABIVALA; HOLT; LONG, 1998; REZENDE; BOMBANA, 1999; SILVER; LOVE; PURTON, 1999; DAVALOU; GUTMANN; NUNN, 1999; FAN; WU; WESSELINK, 2000; AL-DEWANI; HAYES; DUMMER, 2000a, 2000b; GILHOOLY et al., 2000; SMITH et al., 2000), não promovendo a extrusão de material obturador, visto que a sobreobturação tem influência no índice de sucesso do tratamento endodôntico, segundo Swartz, Skidmore e Griffin (1983), Halse e Molven (1987), Seltzer (1988), Sjogren et al. (1990), Odesjo et al. (1990), Smith, Setchell e Harty (1993), Saunders et al. (1997) e Walton e Johnson (1997).

Neste estudo, os preparos dos canais radiculares foram realizados através dos instrumentos ProFile, segundo a seqüência preconizada pela MailleferDentsply, bem como, as técnicas de obturação dos grupos experimentais Thermafil (G1), Obtura ॥ (G2) e Ultrafil 3D (G3), conforme orientações dos 
fabricantes Maillefer-Dentsply, Obtura e Hygenic, respectivamente, enquanto que os espécimes da técnica Fusionada (G4) foram obturados acorde Moura, Otani e Davidowicz (1999/2000).

Particularmente nas técnicas de injeção, conforme instruções dos fabricantes e segundo Nguyen e Ruddle (1994), a agulha ou cânula selecionada deveria alcançar a posição de 3 a $5 \mathrm{~mm}$ do término apical passivamente, justificando assim neste estudo a utilização das cânulas dos grupos G2 (Obtura II) e G3 (Ultrafil 3D), posicionadas a 3mm aquém do CRT.

Na técnica Fusionada (G4) e no grupo controle negativo, bem como, para inserção de cimento nos demais grupos experimentais, foram utilizados cones de guta-percha estandardizados calibrados em régua calibradora de cones marca Maillefer-Dentsply, baseado nos estudos de Davidowicz, Moura e Strefezza (1994) e comprovados nos estudos de Moura et al. (1994), Moura et al. (1995a), Moura et al. (1995b), Carvalho (1998) e Strefezza (1999).

Frente à revista da literatura pertinente, diversos estudos constataram a extrusão apical do material obturador em técnicas de obturação com guta-percha termoplastificada, através de avaliações radiográficas (YEE et al., 1977; JOHNSON, 1978; MARLIN et al., 1981; MARLIN, 1986; GEORGE; MICHANOWICZ; MICHANOWICZ, 1987; LANGELAND et al., 1987; MICHANOWICZ et al., 1989; SOARES; ROCHA, 1993; GUTMANN et al., 1993a; BERGER, 1995; KYTRIDOU; GUTMANN; NUNN, 1999), visuais (YEE et al., 1977; ELDEEB, 1985; LARES; ELDEEB, 1990; HADDIX et al., 1991; CLARK; ELDEEB, 1993; DUMMER et al., 1993; LEUNG; GULABIVALA, 1994a; HOLLAND et al., 1995; LLOYD et al., 1995; SANTA CECILIA; MORAES; BERBERT, 1995; GULABIVALA; HOLT; LONG, 1998; AL-DEWANI; HAYES; DUMMER, 2000a, 
2000b; GILHOOLY et al., 2000, 2001; ABARCA; BUSTOS; NAVIA, 2001; SCHAFER; OLTHOFF, 2002) e microscópicas (YEE et al, 1977; EVANS; SIMON, 1986; MANN; McWALTER, 1987; LANGELAND et al., 1987; LaCOMBE et al., 1988; OLSON; HARTWELL; WELLER, 1989; MOURA, 1990; BUDD; WELLER; KULILD, 1991; GUTMANN et al., 1993b; GENÇOGLU; SAMANI; GUNDAY, 1993; LEUNG; GULABIVALA, 1994b; UTRILLA et al., 1995; DAVALOU; GUTMANN; NUNN, 1999; WU; SLUIS; WESSELINK, 2002; SILVA et al., 2002; LEVITAN; HIMEL; LUCKEY, 2003).

Porém, escassos estudos procuraram quantificar o material obturador extruído, dentre os quais, Ritchie, Anderson e Sakamura (1988) e Holtz e Machado (1998) em canais simulados, enquanto Scott e Vire (1992), Kastakova, Wu e Wesselink (2001) e Wu, Sluis e Wesselink (2002), utilizando dentes humanos extraídos, em que o material extruído foi removido dos ápices radiculares e pesado em balança analítica.

O Laboratório de Metrologia Volumétrica (FGG) realizou a aferição do sistema de mensuração através da pesagem do volume de água destilada em balança analítica digital Sartorius, acorde Ferreira e Ferreira (2003). Convém salientar, que nos trabalhos de Kastakova, Wu e Wesselink (2001) e Wu, Sluis e Wesselink (2002), também foram utilizadas balanças analíticas digitais com modelos semelhantes ao deste estudo.

O critério de avaliação radiográfica foi proposto por Kytridou, Gutmann e Nunn (1999), complementando os critérios estabelecidos por Kersten, Fransman e Thoden van Velzen (1986), que foram utilizados nos estudos de Kersten, Wesselink e Thoden van Velzen (1987), Al-Dewani, Hayes e Dummer (2000b), Gilhooly et al. (2000), Al-Dewani, Hayes e Dummer (2000a) e Gilhooly et al. 
(2001), baseado nas normas da American Association of Endodontists (1994), em que radiograficamente a obturação do sistema de canais radiculares deveria ser densa, tridimensional estendendo-se o mais próximo possível da junção cementodentina-canal.

Os dois examinadores, que avaliaram radiograficamente os espécimes dos grupos experimentais, apresentaram concordância de resultados e foram calibrados baseados no critério proposto por Kytridou, Gutmann e Nunn (1999), sendo essencial a observação de dois examinadores, aumentando a concordância dos resultados, para que não ocorram variações substanciais nas observações que influenciam na interpretação radiográfica dental, acorde Zakariasen, Scott e Jensen (1984) e Lambrianidis (1985).

Em todas as técnicas de guta-percha termoplastificada utilizadas neste estudo, houve extrusão de material obturador em virtude da desobstrução intencional do canal radicular realizada previamente à fase de obturação, impedindo a presença de matriz dentinária apical que poderia evitar a extrusão de material obturador acorde Langeland et al. (1987), Gutmann e Rakusin (1987) e Gatot, Peist e Mozes (1989).

No grupo controle negativo (GCN) não houve variação de volume após a inserção do cone principal de guta-percha calibrado até o CRT, enquanto que no grupo controle positivo (GCP), ocorreu variação de volume após a inserção intencional do cone de guta-percha além do forame, validando, desta forma, o sistema de mensuração, confirmando as variações de registros de volume do material obturador extruído, somente no controle positivo.

Em relação à análise quantitativa do volume de material obturador extruído nos grupos experimentais, apesar da ausência de diferença estatisticamente 
significante entre as médias de volume $(p=0,234)$, os grupos G2 (Obtura II) e G3 (Ultrafil 3D) apresentaram os menores valores de material extruído, 5,0 $\mu$ e $5,3 \mu \mathrm{l}$, respectivamente. Enquanto que os grupos G1 (Thermafil) e G4 (Fusionada) extruíram igualmente em maior quantidade com médias no valor de $6,3 \mu$ l.

Frente à escassez de estudos que avaliaram quantitativamente o volume da extrusão do material obturador, podemos apenas estabelecer relações de resultados quantitativos deste estudo com pesquisas que mensuraram o material extruído através do peso, independentemente das variações inerentes aos diferentes métodos de avaliações.

Neste aspecto, o grupo G1 (Thermafil) apresentou maior quantidade de extrusão de material obturador, cujo resultado está de acordo com Scott e Vire (1992), porém, estes autores constataram diferença estatisticamente significante em relação ao Ultrafil e Obtura, diferentemente dos achados no presente estudo.

Estas variações de resultados podem ter ocorrido em virtude de que os autores anteriormente citados utilizaram, tanto no sistema Obtura como no Ultrafil, posições diferentes de inserção das agulhas ou cânulas (4 a $5 \mathrm{~mm}$ e $6 \mathrm{~mm}$ aquém do CRT, respectivamente) em relação ao posicionamento neste estudo, conforme discutido anteriormente.

Em relação aos resultados da análise qualitativa da freqüência da extrusão de guta-percha e/ou cimento, constatamos que no grupo G1 (Thermafil) houve alta incidência de extrusão de guta-percha e cimento, diferença altamente significativa em comparação com a extrusão somente de cimento $(p<0,001)$, estão de acordo com os resultados visuais de Haddix et al. (1991), Clark e EIDeeb (1993), Dummer et al. (1993), Santa Cecilia, Moraes e Berbert (1995), Gulabivala, Holt e Long (1998), Schafer e Olthoff (2002), adiográficos de Gutmann et al. 
(1993a), Kytridou, Gutmann e Nunn (1999) e microscópicos de Gutmann et al. (1993b) e Silva et al. (2002).

Tais resultados estão em desacordo com os estudos visuais de Lares e EIDeeb (1990), Leung e Gulabivala (1994a) e Abarca, Bustos e Navia (2001), bem como, os achados microscópicos de Gençoglu, Samani e Gunday (1993) e Leung e Gulabivala (1994b), em virtude, provavelmente, das variações existentes nos tipos de amostras (presença de canais curvos), nas temperaturas de aquecimento do Thermafil e na ausência de patência apical.

Enquanto que no grupo G2 (Obtura II) ocorreu a extrusão somente de cimento em todos os espécimes, não ocorrendo extrusão de guta-percha, tais resultados diferem minimamente dos achados microscópicos de Mann e McWalter (1987) que, em canais retos, encontraram extrusão de guta-percha em 10\% dos espécimes, enquanto que a extrusão de cimento não foi computada e em desacordo também dos resultados de Budd, Weller e Kulild (1991) em cujo experimento não foi utilizado cimento.

No grupo G3 (Ultrafil 3D) houve alta incidência de extrusão de guta-percha e cimento, resultados que estão de acordo com os achados visuais de EIDeeb (1985), Al-Dewani, Hayes e Dummer (2000a), radiográficos de George, Michanowicz e Michanowicz (1987), Soares e Rocha (1993) e microscópicos de Moura (1990), Budd, Weller e Kulild. (1991) e Utrilla et al. (1995).

Porém, diferentemente dos resultados microscópicos e visuais de Olson, Hartwell e Weller (1989) e Holland et al. (1995), respectivamente, com baixos índices de extrusão de guta-percha e cimento na técnica Ultrafil, em virtude da inserção de um cone principal de guta-percha previamente à técnica de injeção de guta-percha termoplastificada, como também, diferindo dos resultados 
microscópicos de Gençoglu, Samani e Gunday (1993) em decorrência, provavelmente, das variações de posicionamento das cânulas e consistência da guta-percha.

No grupo G4 (Fusionada) houve ausência de diferença estatisticamente significante na incidência de extrusão de cimento e guta-percha, em comparação com cimento somente $(p=0,726)$, apresentando resultados próximos em percentagem, $47 \%$ e 53\%, respectivamente. Neste grupo, não pudemos estabelecer relações qualitativas e quantitativas com outros autores, em virtude da ausência de pesquisas na literatura com esta técnica, até o momento.

$\mathrm{Na}$ análise qualitativa entre os grupos experimentais frente às freqüências de extrusão visual (sem extrusão e extrusões de cimento; guta-percha; cimento e guta-percha), houve diferença estatisticamente significante entre os grupos G2Obtura II e G3-Ultrafil 3D ( $p<0,001)$, que estão em desacordo com os achados de LaCombe et al. (1988), que não encontraram diferenças significativas, pois, estes autores avaliaram a extrusão de material obturador microscopicamente, sem estabelecer a divisão entre extrusão de cimento e guta-percha com cimento.

Neste aspecto, houve extrusão de guta-percha com cimento nos grupos Thermafil (G1), Ultrafil 3D (G3) e Fusionada (G4), enquanto que no grupo Obtura II (G2) ocorreu somente extrusão de cimento (100\% dos espécimes), indicando semelhança estatística na comparação do grupo Thermafil com os grupos Ultrafil 3D e Fusionada, bem como, diferenças estatisticamente significantes na comparação do Obtura II com os demais grupos.

Convém salientar que não pudemos estabelecer relações com a revista da literatura, na comparação entre os grupos através de avaliações visuais, pois a 
maioria dos autores realizou comparações entre as técnicas citadas com a técnica de condensação lateral.

Ressalta-se, ainda, a fundamental importância em avaliarmos não somente a incidência de extrusão do material obturador, como também a extensão do material extruído, apesar de não ser a proposta deste estudo, visto que Halse e Molven (1987) constataram que o índice de insucessos aumentou significativamente nas extensões maiores de materiais além do ápice radiográfico, bem como, acorde Utrilla et al. (1995) verificando histologicamente, que nas sobreobturações, a reparação do ligamento periodontal foi influenciada proporcionalmente à quantidade de guta-percha extravasada, vindo ao encontro das inter-relações propostas nesta pesquisa.

$\mathrm{Na}$ avaliação radiográfica da qualidade final das obturações com as técnicas termoplastificadas utilizadas neste estudo, identificamos diferenças estatisticamente significantes, nos sentidos vestíbulo-lingual e mésio-distal, na comparação do grupo G2 (Obtura II) com todos os outros grupos experimentais, bem como, ausência de diferenças significativas entre os grupos G1 (Thermafil), G3 (Ultrafil 3D) e G4 (Fusionada) entre si.

Tais resultados foram confirmados, através das diferenças estatisticamente significantes identificadas entre os quatro grupos, para as proporções dos escores 0, 1, 2, 3 e 4, em que o Obtura II (G2) foi o único grupo que apresentou o escore 4 nas avaliações vestíbulo-lingual e mésio-distal com os dois examinadores, bem como, diferenças significativas com todos os outros grupos nos escores 0 e 3 , nos dois sentidos de avaliação, e escore 1 no sentido mésio-distal. 
Desta forma, há evidências de que o grupo Obtura II (G2) produziu obturações endodônticas com qualidades radiográficas inferiores em relação às demais técnicas.

Em relação à variação da qualidade radiográfica final das obturações, nos dois sentidos de observação, apesar de as obturações classificadas com bons escores no sentido vestíbulo-lingual apresentarem piores resultados, no sentido mésio-distal, acorde achados de Kersten, Wesselink e Thoden van Velzen (1987), Al-Dewani, Hayes e Dummer (2000b), Gilhooly et al. (2000), Al-Dewani, Hayes e Dummer (2000a) e Gilhooly et al. (2001), estas variações só foram significativas no grupo G3-Ultrafil 3D ( $p=0,013)$, enquanto que nos demais grupos não houve diferenças estatisticamente significantes, enfatizando assim a necessidade de ótimos escores nas radiografias clínicas para estimar a qualidade final do tratamento endodôntico.

Frente às análises quantitativa de volume e qualitativas de extrusão visual apical, bem como, da qualidade radiográfica final da obturação endodôntica nas técnicas empregadas neste estudo, verificamos que, apesar da ausência de diferença estatisticamente significante entre os demais grupos, a técnica Obtura II (G2) produziu a menor quantidade de material obturador extruído $(5,0 \mu l)$ com incidência de extrusão de cimento em 100\% dos espécimes.

Estabelecendo relação baseada somente nestes dois aspectos, este grupo seria o mais favorável para a obturação termoplastificada, afinal, considerando clinicamente, dentre os fatores que poderiam influenciar no insucesso do tratamento endodôntico, a extrusão de cimento e em quantidades mínimas, teria proporcionalmente menor interferência na reparação da região periapical, do que a extrusão de guta-percha e cimento em quantidades maiores. Porém, frente à 
qualidade radiográfica final da obturação, o grupo G2 (Obtura II) apresentou resultados estatisticamente inferiores às demais técnicas.

Desta forma, os grupos G1 (Thermafil) e G4 (Fusionada), que apresentaram extrusão visual de cimento em 20\% e 53\% dos espécimes, respectivamente, em relação a este aspecto, teriam proporcionalmente resultados clínicos mais favoráveis na reparação periapical, em relação ao grupo G3 (Ultrafil 3D) com incidência de extrusão de guta-percha e cimento em 100\% dos espécimes.

Assim, de modo geral, inter-relacionando os diversos aspectos avaliados neste estudo, podemos considerar que as técnicas Thermafil (G1), Ultrafil 3D (G3) e Fusionada (G4) apresentaram resultados semelhantes em relação ao volume do material obturador extruído e qualidade radiográfica final da obturação, enquanto que as técnicas Thermafil (G1) e Fusionada (G4) exibiram resultados mais favoráveis em relação à freqüência da extrusão visual de guta-percha e/ou cimento.

Convém salientar que estes resultados in vitro devem ser considerados e analisados com cautela, previamente à utilização clínica das técnicas deste estudo, visto que, existem fatores inerentes à pesquisa que não podem ser controlados, tais como, variações anatômicas dos espécimes, destreza manual do operador, dificuldades técnicas, interpretação radiográfica e variações nos métodos de avaliação.

Assim, torna-se claro que são necessários contínuos estudos, no intuito de também avaliar a utilização deste sistema de mensuração de volume de material extruído com outras técnicas e materiais de obturação diferentes, bem como, verificar quantitativamente a extrusão apical, não somente de material obturador, 
mas, também, de substâncias químicas auxiliares ou medicações intracanais, utilizando métodos que minimizem a quantidade de substância extruída na região apical, diminuindo a agressão aos tecidos adjacentes de suporte. 


\section{CONCLUSÕES}




\section{CONCLUSÕES}

Diante do exposto, parece-nos lícito concluir que :

7.1 A introdução da metodologia do sistema de mensuração empregada no presente estudo foi efetiva para quantificar o volume de material obturador extruído, nas técnicas de obturação termoplastificadas Thermafil, Obtura II, Ultrafil 3D e Fusionada.

7.2 Em todas as técnicas utilizadas neste estudo, houve extrusão de material obturador, constatada através de métodos de avaliação quantitativo e qualitativo.

7.3 Em relação à análise quantitativa do volume de material obturador extruído, apesar das variações numéricas entre as médias, não identificamos diferenças estatisticamente significantes entre os grupos experimentais.

7.4 Na análise qualitativa da extrusão visual dos materiais obturadores houve extrusão de guta-percha e cimento nos grupos Thermafil, Ultrafil 3D e Fusionada, enquanto que na técnica Obtura II ocorreu somente extrusão de cimento, indicando semelhança estatística na comparação das freqüências de extrusão do grupo Thermafil com os grupos Ultrafil 3D e Fusionada, bem como, diferenças estatisticamente significantes na comparação do Obtura II com os outros grupos. 
7.5 Na avaliação radiográfica da qualidade final das obturações termoplastificadas desta pesquisa, há evidências de que a técnica Obtura II produziu obturações endodônticas com qualidades estatisticamente inferiores às demais técnicas.

7.6 De modo geral, inter-relacionando os diversos aspectos avaliados neste estudo, podemos considerar que as técnicas Thermafil, Ultrafil 3D e Fusionada apresentaram resultados semelhantes em relação ao volume do material obturador extruído e qualidade radiográfica final da obturação, enquanto que as técnicas Thermafil e Fusionada exibiram resultados mais favoráveis em relação à freqüência da extrusão visual de guta-percha e/ou cimento. 


\section{REFERÊNCIAS}




\section{REFERÊNCIAS ${ }^{1}$}

Abarca AM, Bustos A, Navia M. A comparison of apical sealing and extrusion

between Thermafil and lateral condensation techniques. J Endod 2001;27(11):670-2.

Al-Dewani N, Hayes SJ, Dummer PMH. Comparison of laterally condensed and lowtemperature thermoplasticized gutta-percha root fillings. J Endod 2000a;26(12):7338.

Al-Dewani N, Hayes SJ, Dummer PMH. Evaluation of Trifecta obturation technique. Endod Dent Traumatol 2000b;16(2):75-83.

American Association of Endodontists. Appropriateness of care and quality assurance guidelines. $2^{\mathrm{a}}$.ed. Chicago: AAE; 1994. p. 16-8.

Barkhordar RA, Nguyen NT. Parestesia of the mental nerve after overextension with AH26 and gutta -percha: report of case. J Am Dent Assoc 1985;110(2):202-3.

Bergenholtz G, Lekholm U, Milthon R, Engstrom B. Influence of apical overinstrumentation and overfilling on re-treated root canal. J Endod 1979;5(10):3104.

Berger CR. Thermafil: avaliação clínica . Rev Odontol UNICID 1995;7(1):19-26.

Budd CS, Weller NR, Kulild JC. A comparison of thermoplasticized injectable guttapercha obturation techniques. J Endod 1991;17(6):260-4.

\footnotetext{
${ }^{1}$ De acordo com Estilo Vancouver. Abreviatura de periódicos segundo base de dados MEDLINE.
} 
Carvalho CF. Avaliação comparativa in vivo da qualidade de adaptação de cones de guta-percha estandardizados e calibrados à região apical através da sensação táctil e análise radiográfica (Contribuição para o estudo) [Dissertação de Mestrado]. São Paulo: Faculdade de Odontologia da Universidade Paulista; 1998.

Clark DS, EIDeeb ME. Apical sealing ability of metal versus plastic carrier Thermafil obturators. J Endod 1993;19(1): 4-9.

Davalou S, Gutmann JL, Nunn MH. Assessment of apical and coronal root canal seals using contemporary endodontic obturation and restorative materials and techniques. Int Endod J 1999;32(5):388-96.

Davidowicz H, Moura AAM, Strefezza F. Avaliação do diâmetro "Do" de cones de guta-percha estandardizados e calibrados comparados com limas tipo $k$ através do microscópio comparador. Rev ABO Nac 1994;2(3):181-5.

Dummer PMH, Kelly T, Meghji A, Sheikh I, Vanitchai JT. An in vitro study of the quality of root fillings in teeth obturated by lateral condensation of gutta-percha or Thermafil obturators. Int Endod J 1993;26(2):99-105.

Dummer PMH, Lyle L, Rawle J, Kennedy JK. A laboratory study of root fillings in teeth obturated by lateral condensation of gutta-percha or Thermafil obturators. Int Endod J 1994;27(1):32-8.

EIDeeb M. The sealing ability of injection-molded thermoplasticized gutta-percha. $J$ Endod 1985;11(2):84-6.

Evans JT, Simon JHS. Evaluation of the apical seal produced by injected thermoplasticized gutta-percha in the absence of smear layer and root canal sealer. $\mathrm{J}$ Endod 1986;12(30):101-7.

Fan B, Wu MK, Wesselink PR. Leakage along warm gutta-percha fillings in the apical canals of curved roots. Endod Dent Traumatol2000;16(1):29-33.

Ferreira GL, Ferreira TEGL, palestrantes. Vidraria científica para laboratórios: uso, segurança, normas, calibração volumétrica [Apostila]. In: Seminário de Vidraria Científica para Laboratórios. São Paulo: Expolabor; 2003. 
Gatot A, Peist M, Mozes M. Endodontic overextension produced by injected thermoplasticized gutta-percha. J Endod 1989;15(6):273-4.

Gençoglu N, Samani S, Gunday M. Evaluation of sealing properties of Thermafil and Ultrafil techniques in the absence or presence of smear layer. J Endod 1993;19(12):599-603.

George JW, Michanowicz AE, Michanowicz JP. A method of canal preparation to control apical extrusion of low-temperature thermoplasticized gutta-percha. J Endod $1987 ; 13(1): 18-23$.

Gilhooly RMP, Hayes SJ, Bryant ST, Dummer PMH. Comparison of cold lateral condensation and a warm multiphase gutta-percha technique for obturation curved root canals. Int Endod J 2000;33(5):415-20.

Gilhooly RMP, Hayes SJ, Bryant ST, Dummer PMH. Comparison of lateral condensation and thermomechanically compacted warm $\alpha$-phase gutta-percha with a single cone for obturation curved root canals. Oral Surg Oral Med Oral Pathol Oral Radiol Endod 2001;91(1):89-94.

Gulabivala K. Obturação do sistema de canais radiculares. In: Stock CJR. Atlas colorido e Texto de Endodontia. $2^{\mathrm{a}}$.ed. Trad. de Christa Feller, Elenice A. N. Gonçalves, Ivete J. Abrahão. São Paulo: Artes Médicas; 1996. cap. 9, p. 151-76.

Gulabivala K, Holt R, Long B. An in vitro comparison of thermoplasticised guttapercha obturation techniques with cold lateral condensation. Endod Dent Traumatol 1998;14(6):262-9.

Gutierrez JH, Gigoux C, Escobar F. Histologic reactions to root canal fillings. Oral Surg Oral Med Oral Pathol 1969;28(4):557-60.

Gutmann JL. Clinical, radiographic and histologic perspectives on success and failure in endodontics. Dent Clin North Amer 1992;36(2):379-93.

Gutmann JL, Hovland EJ. Problemas na obturação do canal radicular. In: Gutmann JL, Dumsha TC, Lovdahl PE, Hovland EJ. Solução de problemas em EndodontiaPrevenção, Identificação e Tratamento. $3^{a}$. ed. Trad. de Edson J.L. Moreira. Rio de Janeiro: Guanabara Koogan; 1999. cap. 6, p. 102-27. 
Gutmann JL, Rakusin H. Perspectives on root canal obturation with thermoplasticized injectable gutta-percha. Int Endod J 1987;20(6):261-70.

Gutmann JL, Saunders WP, Saunders EM, Nguyen L. An assessment of the plastic Thermafil obturation technique. Part 1 - Radiographic evaluation of adaptation and placement. Int Endod J 1993a;26(3):173-8.

Gutmann JL, Saunders WP, Saunders EM, Nguyen L. An assessment of the plastic Thermafil obturation technique. Part 2 - Material adaptation and sealability. Int Endod J 1993b;26(3):179-83.

Haddix JE, Jarrel M, Mattison GD, Pink FE. An in vitro investigation of the apical seal produced by a new thermoplasticized gutta-percha obturation technique.

Quintessence Int 1991;22(2):159-63.

Halse A, Molven O. Overextended gutta-percha and Kloroperka N-O root canal fillings. Acta Odontol Scand 1987;45(3):171-7.

Holland R, Murata SS, Saito CMT, Desan Junior E. Infiltração marginal apical após a obturação de canal com três tipos diferentes de guta-percha do sistema Ultrafil. Rev Odontol UNESP 1995;24(1):39-45.

Holtz AP, Machado MEL. Estudo da extrusão apical em canais simulados obturados pela guta-percha termoplastificada (Successfil). JBC 1998;2(12):69-72.

Hygenic. Ultrafil 3D - Three dimensional injectable gutta-percha system [Catálogo do produto]. Mahwah; s.d.

Ingle JI, West JD. Obturation of the radicular space. In: Ingle JI, Bakland LK. Endodontics. $4^{\mathrm{a}}$.ed. Philadelphia: Lea \& Febiger; 1994. cap 4, p. 228-319.

Johnson B. A new gutta-percha technique. J Endod 1978;4(6):184-8.

Kastakova A, Wu MK, Wesselink PR. An in vitro experiment on the effect of an attempt to create an apical matrix during root canal preparation on coronal leakage and material extrusion. Oral Surg Oral Med Oral Pathol Oral Radiol Endod 2001;91(4):462-7. 
Kersten HW, Fransman R, Thoden van Velzen SK. Thermomechanical compaction of gutta-percha. I. A comparison of several compaction procedures. Int Endod J 1986;19(3):125-33.

Kersten HW, Wesselink PR, Thoden van Velzen SK. The diagnostic reliability of the buccal radiograph after root canal filling. Int Endod J 1987;20(1):20-4.

Kytridou V, Gutmann JL, Nunn MH. Adaptation and sealability of two contemporary obturation techniques in the absence of the dentinal smear layer. Int Endod $\mathrm{J}$ 1999;32(6):464-74.

LaCombe JS, Campbell AD, Hicks ML, Pelleu GB. A comparison of the apical seal produced by two thermoplasticized injectable gutta-percha techniques. J Endod 1988;14(9):445-50.

Lage Marques JLS. Avaliação da metodologia de impermeabilização radicular externa com vistas ao estudo da permeabilidade dentinária e marginal [Tese de Doutorado]. São Paulo: Faculdade de Odontologia da Universidade de São Paulo; 1992.

Lambrianidis T. Observer variations in radiographic evaluation of endodontic therapy. Endod Dent Traumatol 1985;1(6):235-41.

Langeland K, Liao K, Costa N, Pascon EA. Efficacy of Obtura and Ultrafil root filling devices[abstract 32]. J Endod 1987;13(3):135.

Lares C, EIDeeb ME. The sealing ability of the Thermafil obturation technique. J Endod 1990;16(10):474-9.

Leung SF, Gulabivala K. An in vitro evaluation of the influence of canal curvature on the sealing ability of Thermafil. Int Endod J 1994a;27(4):190-6.

Leung SF, Gulabivala K. An in vitro evaluation of the influence of temperature of plasticization on the sealing ability of Thermafil. Int Endod J 1994b;27(1):39-44.

Levitan ME, Himel VT, Luckey JB. The effect of insertion rates on fill length and adaptation of a thermoplasticized gutta-percha technique. J Endod 2003;29(8):505-8. 
Lloyd A, Thompson J, Gutmann JL, Dummer, PMH. Sealability of the Trifecta technique in the presence or absence of a smear layer. Int Endod J 1995;28(1):3540.

Mann SR, McWalter GM. Evaluation of apical seal and placement control in straight and curved canals obturated by laterally condensed and thermoplasticized guttapercha. J Endod 1987;13(1):10-7.

Marlin J. Injectable standard gutta-percha as a method of filling root canal system. J Endod 1986;12(8):354-8.

Marlin J, Krakow AA, Desilets RP, Gron P. Clinical use of injection-molded thermoplasticized gutta-percha for obturation of the root canal system: a preliminary report. J Endod 1981;7(6):277-81.

Maillefer-Dentsply. Sistema Maillefer Profile [Catálogo do produto]. Petrópolis; s.d.

Maillefer-Dentsply. Sistema Maillefer Thermafil [Catálogo do produto]. Petrópolis; s.d.

Michanowicz AE, Michanowicz JP, Michanowicz AM, Czonstkowsky M, Zullo TP. Clinical evaluation of low-temperature thermoplasticized injectable gutta-percha: a preliminary report. J Endod 1989;15(12):602-7.

Milas VB. História. In: Cohen S, Burns R. Caminhos da polpa. $2^{\mathrm{a}}$. ed. Trad. de Sylvio Bevilacqua. Rio de Janeiro: Guanabara Koogan; 1982. cap. 25, p. 652-65.

Molyvdas I, Zervas P, Lambrianidis T, Veis A. Periodontal tissue reactions following root canal obturation with an injection-thermoplasticized gutta-percha technique. Endod Dent Traumatol 1989;5(1):32-7.

Moura AAM. Análise comparativa in vitro da qualidade do selamento marginal da obturação de canais radiculares segundo as técnicas convencional e Sistema Ultrafil (Contribuição para o estudo) [Tese de Livre-Docência]. São Paulo: Faculdade de Odontologia da Universidade de São Paulo; 1990.

Moura AAM, Otani AY, Davidowicz H. Fused gutta-percha technique: root canal filling procedure with thermoplasticized low-temperature gutta-percha. Braz Endod J 1999/2000;4(1/2):29-32. 
Moura AAM, Carvalho CF, Davidowicz H, Santos M. Avaliação in vitro da adaptação apical através da sensação táctil entre cones de guta-percha estandardizados e calibrados adaptados à região apical. Rev ABO 1995a;3(2):119-22.

Moura AAM, Carvalho CF, Novelli M, Borra RC. Avaliação comparativa in vitro da qualidade do selamento marginal apical de cones estandardizados e cones secundários calibrados com régua calibradora Maillefer. RPG 1995b;2(2):59-65.

Moura AAM, Carvalho CF, Santos M, Davidowicz H. Avaliação in vitro através da análise radiográfica de cones de guta-percha estandardizados e calibrados à região apical. Rev Inst Cienc Saúde 1994;12(1):7-11.

Moura AAM, Sampaio JMP, Paiva JG, Laguna S, Pesce HF. Análise da qualidade da obturação do canal radicular empregando guta-percha termoplastificada a baixa temperatura (Sistema Ultrafil). Rev Fac Odontol FZL 1989;1(2):75-82.

Nguyen NT, Ruddle CJ. Obturation of root canal system. In: Cohen S, Burns RC. Pathways of the pulp. $6^{\text {a }}$ ed. St Louis: Mosby;1994. cap. 9, p. 219-71.

Odesjo B, Hellden L, Salonen L, Langeland K. Prevalence of previous endodontic treatment, technical standard and occurrence of periapical lesions in a randomly selected adult, general population. Endod Dent Traumatol 1990;6(6):265-72.

Olson AK, Hartwell GR, Weller N. Evaluation of the controlled placement of injected thermoplasticized gutta-percha. J Endod 1989;15(7):306-9.

Paiva JG, Antoniazzi JH. Endodontia: bases para a prática clínica. $2^{a}$ ed. São Paulo: Artes Médicas; 1993.

Rezende CB, Bombana AC. Avaliação in vitro da capacidade de selamento marginal apical de uma técnica de obturação empregando guta-percha termoplastificada associada ou não a cimento endodôntico. RPG 1999;6(2):132-8.

Ricucci D, Langeland K. Apical limit of root canal instrumentation and obturation. Part 2. A histological stud y. Int Endod J 1998;31(6):394-409.

Ritchie GM, Anderson DM, Sakamura JS. Apical extrusion of thermoplasticized guttapercha used as a root canal filling. J Endod 1988;14(3):128-32. 
Santa Cecilia M, Moraes IG, Berbert A. Extrusão apical de material obturador observado na técnica Thermafil. Rev Fac Odontol Bauru 1995;3(1/4):89-93.

Saunders WP, Saunders EM, Sadiq J, Cruickshank E. Technical standard of root canal treatment in an adult Scottish sub-population. Br Dent J 1997;182(10):382-6.

Schafer E, Olthoff G. Effect of three different sealers on the sealing ability of both Thermafil obturators and cold laterally compacted gutta-percha. J Endod 2002;28(9):638-42.

Scott AC, Vire DE. An evaluation of the ability of a dentin plug to control extrusion of thermoplasticized gutta-percha. J Endod 1992;18(2):52-7.

Seltzer S. Endodontology: biologic considerations in endodontic procedures. $2^{\mathrm{a}}$. ed. Philadelphia: Lea \& Febiger; 1988.

Silva D, Endal U, Reynaud A, Portenier I, Orstavik D, Haapasalo M. A comparative study of lateral condensation, heat-softened gutta-percha and a modified master cone heat-softened backfilling technique. Int Endod J 2002;35(12):1005-11.

Silver GK, Love RM, Purton DG. Comparison of two vertical condensation obturation techniques: Touch'n Heat modified and System B. Int Endod J 1999;32(4):287-95.

Sjogren U, Hagglund B, Sundqvist G, Wing K. Factors affecting the long-term results of endodontic treatment. J Endod 1990;16(10):498-504.

Smith CS, Setchell DJ, Harty FJ. Factors influencing the success of conventional root canal therapy - a five-year retrospective study. Int Endod J 1993;26(6):321-33.

Smith RS, Weller RN, Loushine RJ, Kimbrough WF. Effect of varying the depth of heat application on the adaptability of gutta-percha during warm vertical compaction. J Endod 2000;26(11):668-72.

Soares IJ, Rocha MJC. Avaliação do selamento apical de obturações radiculares realizadas com guta-percha termoplastificada através do sistema Ultrafil. Rev Bras Odontol 1993;50(2):19-25. 
Strefezza F. Avaliação das áreas dos orifícios de réguas calibradoras de pontas de guta-percha, Maillefer e Prisma, frente aos padrões de estandardização e esterilização [Dissertação de Mestrado]. São Paulo: Faculdade de Odontologia da Universidade de São Paulo; 1999.

Swartz DB, Skidmore AE, Griffin JA. Twenty years of endodontic success and failure. J Endod 1983;9(5):198-202.

Tavares T, Soares IJ, Silveira NL. Reaction of rat subcutaneous tissue to implants of gutta-percha for endodontic use. Endod Dent Traumatol 1994;10(4):174-8.

Utrilla LS, Leonardo MR, Cabral MMG, Silva LAB. Estudo comparativo do comportamento dos tecidos apicais e periapicais frente a duas técnicas de obturação de canais radiculares com guta-percha termoplastificada. Rev Bras Odontol 1995;52(2):32-8.

Walton RE, Johnson WT. Obturação. In: Walton RE, Torabinejad M. Princípios e prática em Endodontia. Trad. de Ana J. Perrotti Garcia. São Paulo:

Santos;1997.cap.14, p. 234-59.

Wu MK, Sluis LWM, Wesselink PR. A preliminary study of the percentage of gutta percha filled area in the apical canal filled with vertically compacted warm guttapercha. Int Endod J 2002;35(6):527-35.

Yee FS, Marlin J, Krakow AA, Gron P. Three-dimensional obturation of root canal using injection-molded, thermoplasticized dental gutta-percha. J Endod 1977;3(5):168-74.

Zakariasen KL, Scott DA, Jensen JR. Endodontic recall radiographs: How reliable is our interpretation of endodontic success or failure and what factors affect our reliability? Oral Surg Oral Med Oral Pathol 1984;57(3):343-7. 
APÊNDICES 
Tabela Ap.1 - Valores de volume, antes e após a obturação e diferença entre as duas mensurações, indicando o volume de material obturador extruído, expresso em microlitros $(\mu \mathrm{l})$, no grupo experimental G1 (Thermafil).

\begin{tabular}{c|c|c|c}
\hline $\begin{array}{c}\text { Espécimes } \\
\left(\mathbf{n}^{\text {os }}\right)\end{array}$ & $\begin{array}{c}\text { Volumes da } \\
\text { Antes } \\
\text { Obturação }\end{array}$ & $\begin{array}{c}\text { Após a } \\
\text { Obturação }\end{array}$ & $\begin{array}{c}\text { Diferença } \\
\text { (Volume } \\
\text { Extruído) }\end{array}$ \\
\hline 1 & 3,7 & 12,2 & 8,5 \\
2 & 6,4 & 11,8 & 5,4 \\
3 & 6,1 & 15,0 & 8,9 \\
4 & 7,5 & 14,9 & 7,4 \\
5 & 3,6 & 7,9 & 4,3 \\
6 & 3,2 & 9,4 & 6,2 \\
7 & 4,0 & 6,4 & 2,4 \\
8 & 4,6 & 9,0 & 4,4 \\
9 & 13,7 & 19,5 & 5,8 \\
10 & 8,6 & 13,5 & 4,9 \\
11 & 7,6 & 13,1 & 5,5 \\
12 & 7,6 & 15,1 & 7,5 \\
13 & 6,2 & 13,4 & 7,2 \\
14 & 6,2 & 14,2 & 8,0 \\
15 & 7,1 & 15,5 & 8,4 \\
\hline
\end{tabular}


Tabela Ap.2 - Valores de volume, antes e após a obturação e diferença entre as duas mensurações, indicando o volume de material obturador extruído, expresso em microlitros ( $\mu \mathrm{l})$, no grupo experimental G2 (Obtura II).

\begin{tabular}{c|c|c|c}
\hline $\begin{array}{c}\text { Espécimes } \\
\left(\mathbf{n}^{\text {os }}\right)\end{array}$ & $\begin{array}{c}\text { Antes da } \\
\text { Obturação }\end{array}$ & $\begin{array}{c}\text { Após a } \\
\text { Obturação }\end{array}$ & $\begin{array}{c}\text { Diferença } \\
\text { (Volume } \\
\text { Extruído) }\end{array}$ \\
\hline 1 & 3,8 & 9,8 & 6,0 \\
2 & 7,2 & 14,2 & 7,0 \\
3 & 5,5 & 8,0 & 2,5 \\
4 & 3,0 & 6,1 & 3,1 \\
5 & 3,6 & 14,5 & 10,9 \\
6 & 6,8 & 12,4 & 5,6 \\
7 & 4,7 & 11,9 & 7,2 \\
8 & 7,9 & 11,1 & 3,2 \\
9 & 7,8 & 13,6 & 5,8 \\
10 & 4,0 & 8,9 & 4,9 \\
11 & 4,0 & 5,8 & 1,8 \\
12 & 3,9 & 9,8 & 5,9 \\
13 & 6,7 & 8,1 & 1,4 \\
14 & 4,8 & 9,1 & 4,3 \\
15 & 6,0 & 11,2 & 5,2 \\
\hline
\end{tabular}


Tabela Ap.3 - Valores de volume, antes e após a obturação e diferença entre as duas mensurações, indicando o volume de material obturador extruído, expresso em microlitros ( $\mu \mathrm{l})$, no grupo experimental G3 (Ultrafil 3D).

\begin{tabular}{c|c|c|c}
\hline $\begin{array}{c}\text { Espécimes } \\
\left(\mathbf{n}^{\text {os })}\right.\end{array}$ & $\begin{array}{c}\text { Volumes da } \\
\text { Obturação }\end{array}$ & $\begin{array}{c}\text { Após a } \\
\text { Obturação }\end{array}$ & $\begin{array}{c}\text { Diferença } \\
\text { (Volume } \\
\text { Extruído) }\end{array}$ \\
\hline 1 & 5,8 & 9,8 & 4,0 \\
2 & 9,4 & 15,0 & 5,6 \\
3 & 6,7 & 14,7 & 8,0 \\
4 & 6,7 & 18,5 & 11,8 \\
5 & 2,0 & 4,8 & 2,8 \\
6 & 2,8 & 5,2 & 2,4 \\
7 & 3,0 & 8,0 & 5,0 \\
8 & 8,0 & 11,2 & 3,2 \\
9 & 3,9 & 8,7 & 4,8 \\
10 & 10,6 & 16,0 & 5,4 \\
11 & 6,8 & 13,0 & 6,2 \\
12 & 9,8 & 15,8 & 6,0 \\
13 & 4,4 & 8,4 & 4,0 \\
14 & 6,9 & 9,0 & 2,1 \\
15 & 10,0 & 17,5 & 7,5 \\
\hline
\end{tabular}


Tabela Ap.4 - Valores de volume, antes e após a obturação e diferença entre as duas mensurações, indicando o volume de material obturador extruído, expresso em microlitros $(\mu \mathrm{l})$, no grupo experimental G4 (Fusionada).

\begin{tabular}{c|c|c|c}
\hline $\begin{array}{c}\text { Espécimes } \\
\left(\mathbf{n}^{\text {os })}\right.\end{array}$ & $\begin{array}{c}\text { Antes da } \\
\text { Obturação }\end{array}$ & $\begin{array}{c}\text { Após a } \\
\text { Obturação }\end{array}$ & $\begin{array}{c}\text { Diferença } \\
\text { (Volume } \\
\text { Extruído) }\end{array}$ \\
\hline 1 & 5,1 & 11,9 & 6,8 \\
2 & 4,0 & 7,7 & 3,7 \\
3 & 11,0 & 15,7 & 4,7 \\
4 & 11,0 & 16,6 & 5,6 \\
5 & 5,0 & 9,9 & 4,9 \\
6 & 5,8 & 11,7 & 5,9 \\
7 & 4,6 & 13,6 & 9,0 \\
8 & 6,2 & 13,8 & 7,6 \\
9 & 12,7 & 17,3 & 4,6 \\
10 & 7,3 & 16,0 & 8,7 \\
11 & 6,1 & 10,0 & 3,9 \\
12 & 7,7 & 15,9 & 8,2 \\
13 & 9,5 & 16,9 & 7,4 \\
14 & 5,2 & 14,2 & 9,0 \\
15 & 4,6 & 8,8 & 4,2 \\
\hline
\end{tabular}


Tabela Ap.5 - Valores de volume, antes e após a inserção do cone principal de guta-percha e diferença entre as duas mensurações, indicando o volume de material obturador extruído, expresso em microlitros ( $\mu \mathrm{l})$, no grupo controle negativo (GCN).

\begin{tabular}{c|c|c|c}
\hline $\begin{array}{c}\text { Espécimes } \\
\left(\mathbf{n}^{\text {os }}\right)\end{array}$ & $\begin{array}{c}\text { Antes do } \\
\text { Cone } \\
\text { Principal }\end{array}$ & $\begin{array}{c}\text { Após o } \\
\text { Cone } \\
\text { Principal }\end{array}$ & $\begin{array}{c}\text { Diferença } \\
\text { (Volume } \\
\text { Extruído) }\end{array}$ \\
\hline 1 & 7,8 & 7,8 & 0,0 \\
2 & 12,0 & 12,0 & 0,0 \\
\hline
\end{tabular}

Tabela Ap.6 - Valores de volume, antes e após a inserção do cone principal de guta-percha e diferença entre as duas mensurações, indicando o volume de material obturador extruído, expresso em microlitros $(\mu \mathrm{l})$, no grupo controle positivo (GCP).

\begin{tabular}{c|c|c|c}
\hline $\begin{array}{c}\text { Espécimes } \\
\left(\mathbf{n}^{\text {os }}\right)\end{array}$ & $\begin{array}{c}\text { Antes do } \\
\text { Cone } \\
\text { Principal }\end{array}$ & $\begin{array}{c}\text { Após o } \\
\text { Cone } \\
\text { Principal }\end{array}$ & $\begin{array}{c}\text { Diferença } \\
\text { (Volume } \\
\text { Extruído) }\end{array}$ \\
\hline 1 & 7,8 & 8,6 & 0,8 \\
2 & 12,0 & 12,2 & 0,2 \\
\hline
\end{tabular}


Tabela Ap.7 -Volume do material obturador extruído, expresso em microlitros $(\mu \mathrm{l})$.

\begin{tabular}{c|c|c|c|c}
\hline \begin{tabular}{c|c|c|} 
Espécimes \\
$\left(\mathbf{n}^{\text {os }}\right)$
\end{tabular} & $\begin{array}{c}\text { Thermafil } \\
\text { (G1) }\end{array}$ & $\begin{array}{c}\text { Obtura II } \\
\text { (G2) }\end{array}$ & $\begin{array}{c}\text { Ultrafil 3D } \\
\text { (G3) }\end{array}$ & $\begin{array}{c}\text { Fusionada } \\
\text { (G4) }\end{array}$ \\
\hline 1 & & & & \\
\hline 2 & 8,5 & 6,0 & 4,0 & 6,8 \\
3 & 5,4 & 7,0 & 5,6 & 3,7 \\
4 & 8,9 & 2,5 & 8,0 & 4,7 \\
5 & 7,4 & 3,1 & 11,8 & 5,6 \\
6 & 4,3 & 10,9 & 2,8 & 4,9 \\
7 & 6,2 & 5,6 & 2,4 & 5,9 \\
8 & 2,4 & 7,2 & 5,0 & 9,0 \\
9 & 4,4 & 3,2 & 3,2 & 7,6 \\
10 & 5,8 & 5,8 & 4,8 & 4,6 \\
11 & 4,9 & 4,9 & 5,4 & 8,7 \\
12 & 5,5 & 1,8 & 6,2 & 3,9 \\
13 & 7,5 & 5,9 & 6,0 & 8,2 \\
14 & 7,2 & 1,4 & 4,0 & 7,4 \\
15 & 8,0 & 4,3 & 2,1 & 9,0 \\
\hline Média Total & 8,4 & 5,2 & 7,5 & 4,2 \\
\hline
\end{tabular}


Tabela Ap.8 - Teste de aderência à curva normal para os volumes de material obturador extruído dos grupos experimentais.

A. Freqüências por intervalos de classe :

\begin{tabular}{|c|c|c|c|c|c|c|c|}
\hline Intervalos de classe & $M-3 s$ & $M-2 s$ & $M-1 s$ & Média & $M+1 s$ & $M+2 s$ & $M+3 s$ \\
\hline Curva normal & 0,44 & 5,40 & 24,20 & 39,89 & 24,20 & 5,40 & 0,44 \\
\hline Curva experimental & 0,00 & 3,33 & 31,67 & 35,00 & 26,67 & 0,00 & 3,33 \\
\hline
\end{tabular}

B. Cálculo do Quiquadrado

Graus de Liberdade:

Valor do Quiquadrado :

Probabilidade de $\mathrm{HO}$ :
4

9,35

$5,30 \%$
Interpretação :

A distribuição amostral testada é normal 
Tabela Ap.9 - Freqüências da extrusão visual de guta-percha e/ou cimento nos grupos experimentais, expressos em valores.

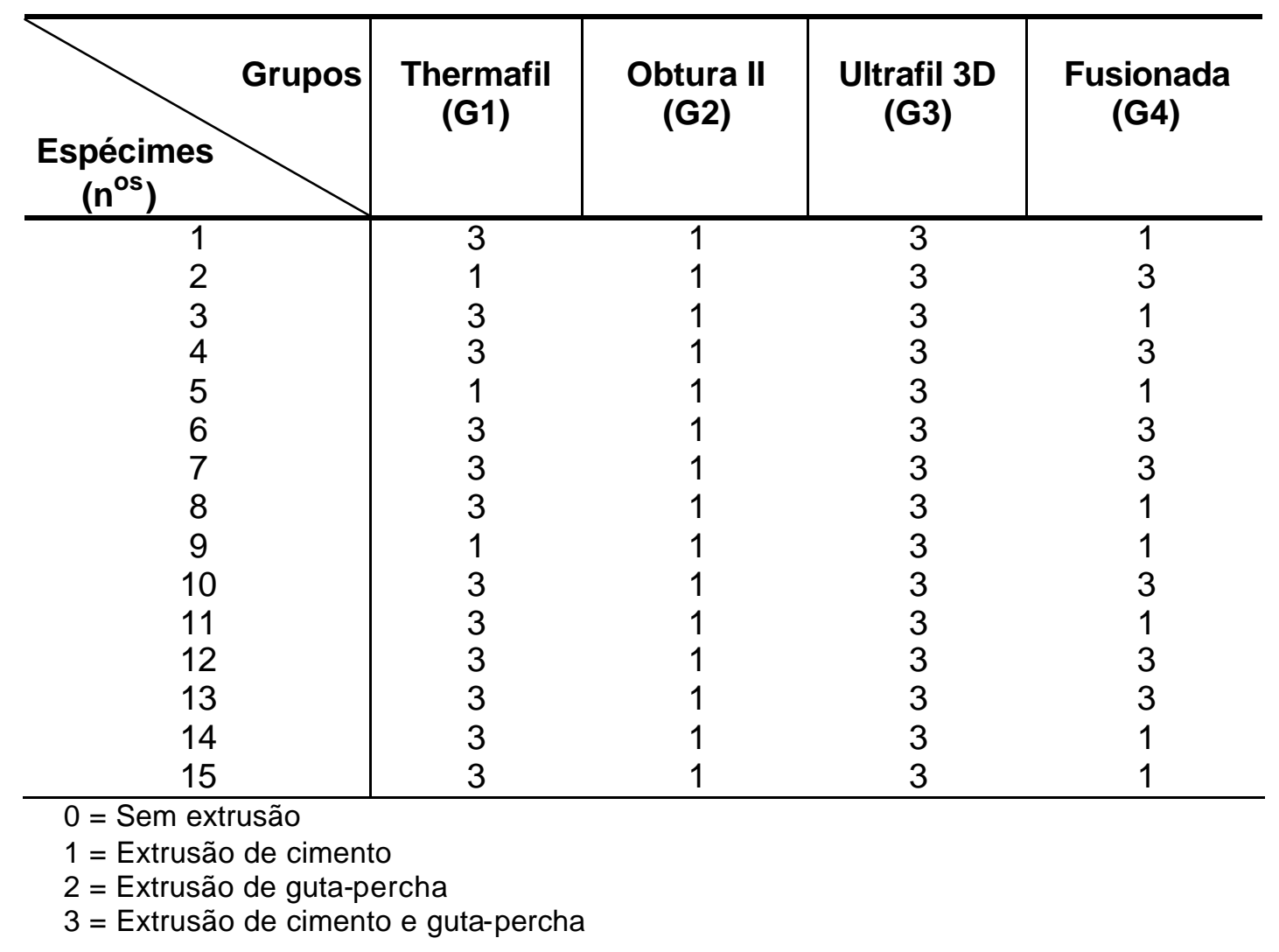


Tabela Ap.10 - Teste de t de Student das médias das proporções da extrusão visual de cimento e guta-percha em comparação com cimento nos grupos experimentais G1 (Thermafil) e G4 (Fusionada).

\begin{tabular}{c|c|c|c}
\hline Grupos & $\mathbf{t}$ & G.L. & Sig.(p) \\
\hline Thermafil(G1) & $-3,969$ & 28,000 & $<0,001$ \\
Fusionada(G4) & 0,354 & 28,000 & 0,726 \\
\hline
\end{tabular}

Tabela Ap.11 - Teste de Kruskal-Wallis das freqüências da extrusão visual dos grupos experimentais.

\begin{tabular}{c|c|c}
\hline Qui-quadrado & G.L. & Sig.(p) \\
\hline 34,439 & 3 & $<0,001$ \\
\hline
\end{tabular}


Tabela Ap.12 - Freqüências da avaliação radiográfica final da obturação nos grupos experimentais do Examinador I, expressos em escores.

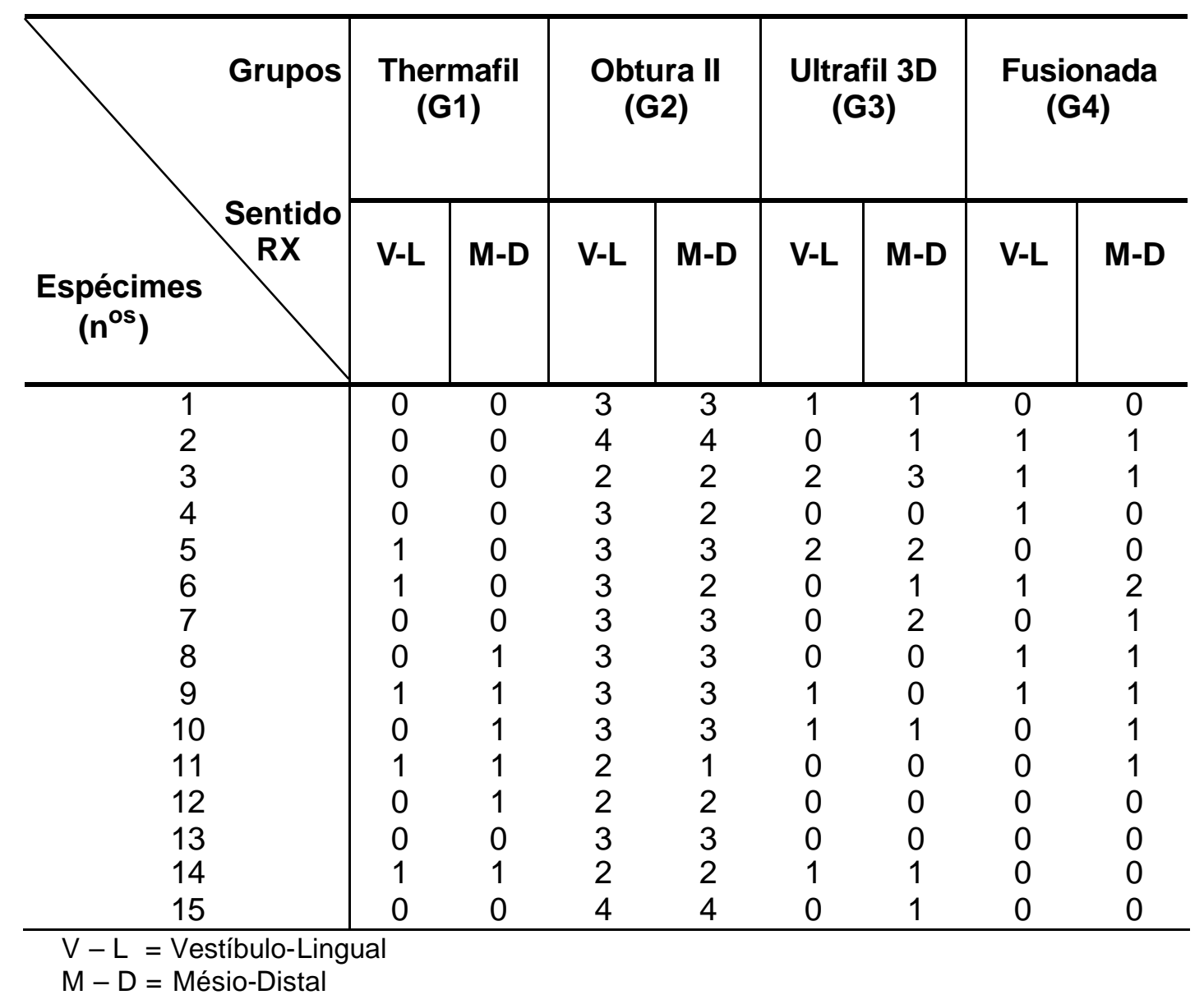


Tabela Ap.13 - Freqüências da avaliação radiográfica final da obturação nos grupos experimentais do Examinador II, expressos em escores.

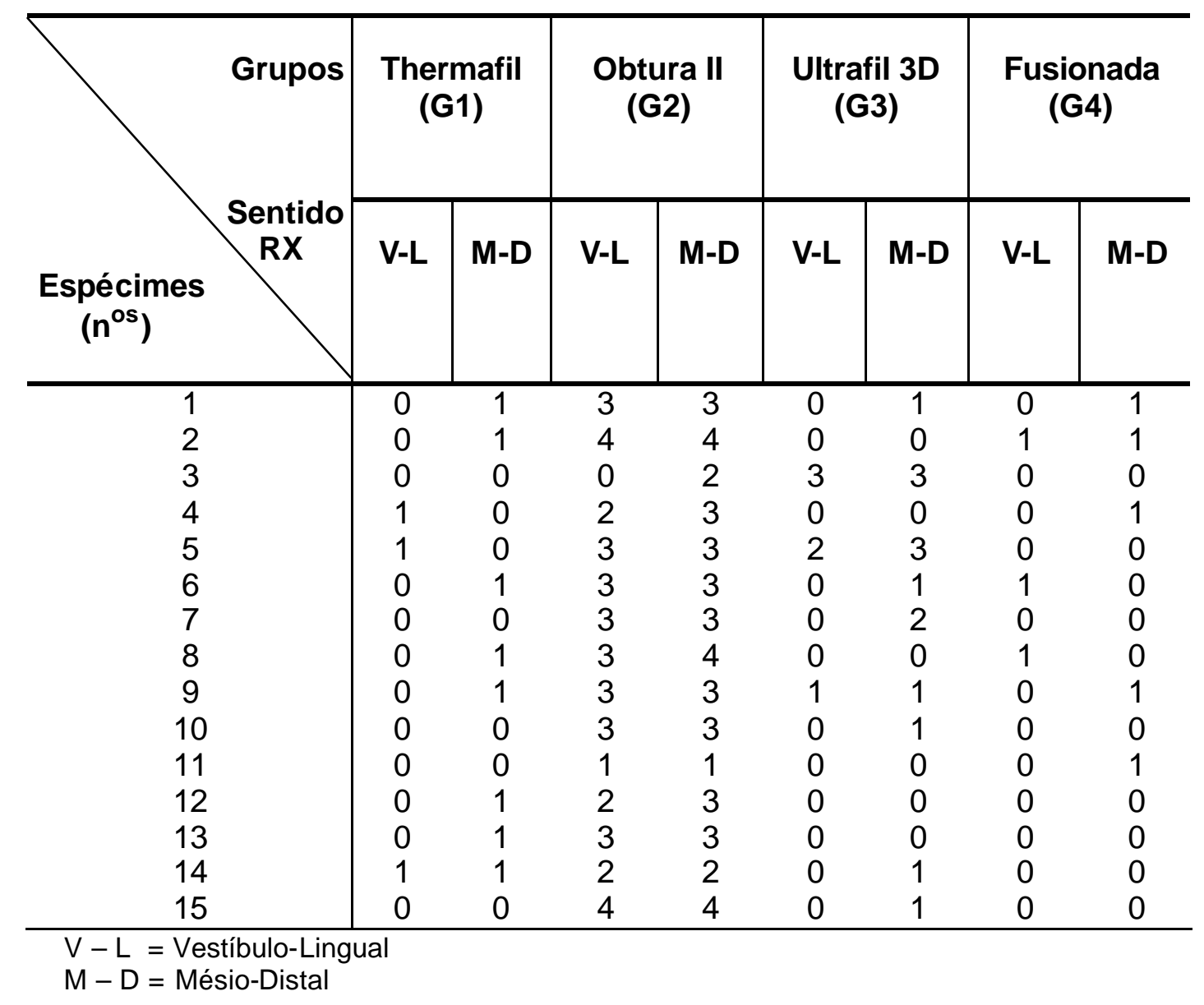


Tabela Ap.14 - Teste dos Postos Sinalizados de Wilcoxon das avaliações radiográficas entre os dois examinadores, para cada grupo experimental nos sentidos vestíbulo-lingual e mésio-distal.

\begin{tabular}{c|c}
\hline Sentido RX / Grupos & Sig.(p) \\
\hline Vestíbulo-Lingual G1 (Thermafil) & 0,317 \\
Mésio-Distal G1 (Thermafil) & 0,414 \\
Vestíbulo-Lingual G2 (Obtura II) & 0,102 \\
Mésio-Distal G2 (Obtura II) & 0,046 \\
Vestíbulo-Lingual G3 (Ultrafil 3D) & 0,317 \\
Mésio-Distal G3 (Ultrafil 3D) & 0,564 \\
Vestíbulo-Lingual G4 (Fusionada) & 0,083 \\
Mésio-Distal G4 (Fusionada) & 0,206 \\
\hline
\end{tabular}

Tabela Ap.15 - Teste de Kruskal-Wallis das avaliações radiográficas dos grupos experimentais nos sentidos vestíbulo-lingual e mésio-distal.

\begin{tabular}{ccc|c}
\hline Sentido RX & Qui-quadrado & G.L. & Sig.(p) \\
\hline Vestíbulo-lingual & 34,679 & 3 & $<0,001$ \\
Mésio-Distal & 31,653 & 3 & $<0,001$ \\
\hline
\end{tabular}


Tabela Ap.16 - Teste de Análise de Variância (ANOVA) das proporções de escores das avaliações radiográficas dos grupos experimentais, nos sentidos vestíbulolingual e mésio-distal.

\begin{tabular}{|c|c|c|c|c|c|c|c|}
\hline Sentido RX & Escores & $\begin{array}{l}\text { Fonte de } \\
\text { variação }\end{array}$ & $\begin{array}{l}\text { Soma de } \\
\text { Quadr. }\end{array}$ & G.L. & $\begin{array}{l}\text { Quadr. } \\
\text { Médios }\end{array}$ & (F) & $\begin{array}{l}\text { Sig. } \\
\text { (p) }\end{array}$ \\
\hline \multirow[t]{5}{*}{$\begin{array}{l}\text { Vestíbulo - } \\
\text { Lingual }\end{array}$} & 0 & $\begin{array}{l}\text { Entre grupos } \\
\text { Resíduo } \\
\text { Total }\end{array}$ & $\begin{array}{l}10,358 \\
19,433 \\
29,792\end{array}$ & $\begin{array}{c}3 \\
116 \\
119\end{array}$ & $\begin{array}{l}3,453 \\
0,168\end{array}$ & 20,610 & $<0,001$ \\
\hline & 1 & $\begin{array}{l}\text { Entre grupos } \\
\text { Resíduo } \\
\text { Total }\end{array}$ & $\begin{array}{c}1,292 \\
17,300 \\
18,592\end{array}$ & $\begin{array}{c}3 \\
116 \\
119\end{array}$ & $\begin{array}{l}0,431 \\
0,149\end{array}$ & 2,887 & 0,039 \\
\hline & 2 & $\begin{array}{l}\text { Entre grupos } \\
\text { Resíduo } \\
\text { Total }\end{array}$ & $\begin{array}{l}1,100 \\
8,067 \\
9,167\end{array}$ & $\begin{array}{c}3 \\
116 \\
119\end{array}$ & $\begin{array}{c}0,367 \\
6,954 \mathrm{E}-02\end{array}$ & 5,273 & 0,002 \\
\hline & 3 & $\begin{array}{l}\text { Entre grupos } \\
\text { Resíduo } \\
\text { Total }\end{array}$ & $\begin{array}{c}6,967 \\
8,333 \\
15,300\end{array}$ & $\begin{array}{c}3 \\
116 \\
119\end{array}$ & $\begin{array}{c}2,322 \\
7,184 \mathrm{E}-02\end{array}$ & 32,325 & $<0,001$ \\
\hline & 4 & $\begin{array}{l}\text { Entre grupos } \\
\text { Resíduo } \\
\text { Total }\end{array}$ & $\begin{array}{l}0,400 \\
3,467 \\
3,867\end{array}$ & $\begin{array}{c}3 \\
116 \\
119\end{array}$ & $\begin{array}{c}0,133 \\
2,989 \mathrm{E}-02\end{array}$ & 4,462 & 0,005 \\
\hline \multirow[t]{5}{*}{$\begin{array}{l}\text { Mésio - } \\
\text { Distal }\end{array}$} & 0 & $\begin{array}{c}\text { Entre grupos } \\
\text { Resíduo } \\
\text { Total }\end{array}$ & $\begin{array}{c}6,092 \\
22,033 \\
28,125\end{array}$ & $\begin{array}{c}3 \\
116 \\
119\end{array}$ & $\begin{array}{l}2,031 \\
0,190\end{array}$ & 10,690 & $<0,001$ \\
\hline & 1 & $\begin{array}{c}\text { Entre grupos } \\
\text { Resíduo } \\
\text { Total }\end{array}$ & $\begin{array}{c}2,933 \\
23,733 \\
26,667\end{array}$ & $\begin{array}{c}3 \\
116 \\
119\end{array}$ & $\begin{array}{l}0,978 \\
0,205\end{array}$ & 4,779 & 0,004 \\
\hline & 2 & $\begin{array}{c}\text { Entre grupos } \\
\text { Resíduo } \\
\text { Total }\end{array}$ & $\begin{array}{l}0,958 \\
9,033 \\
9,992\end{array}$ & $\begin{array}{c}3 \\
116 \\
119\end{array}$ & $\begin{array}{c}0,319 \\
7,787 \mathrm{E}-02\end{array}$ & 4,102 & 0,008 \\
\hline & 3 & $\begin{array}{c}\text { Entre grupos } \\
\text { Resíduo } \\
\text { Total }\end{array}$ & $\begin{array}{c}5,825 \\
10,167 \\
15,992\end{array}$ & $\begin{array}{c}3 \\
116 \\
119\end{array}$ & $\begin{array}{c}1,942 \\
8,764-E 02\end{array}$ & 22,154 & $<0,001$ \\
\hline & 4 & $\begin{array}{l}\text { Entre grupos } \\
\text { Resíduo } \\
\text { Total }\end{array}$ & $\begin{array}{l}0,625 \\
4,167 \\
4,792\end{array}$ & $\begin{array}{c}3 \\
116 \\
119\end{array}$ & $\begin{array}{c}0,208 \\
3,592 \mathrm{E}-02\end{array}$ & 5,800 & 0,001 \\
\hline
\end{tabular}


Tabela Ap.17 - Teste dos Postos Sinalizados de Wilcoxon das avaliações radiográficas, entre os sentidos vestíbulo-lingual e mésio-distal nos grupos experimentais.

\begin{tabular}{l|c|c|c|c}
\hline Grupos & $\begin{array}{c}\text { Thermafil } \\
\text { (G1) }\end{array}$ & $\begin{array}{c}\text { Obtura II } \\
\text { (G2) }\end{array}$ & $\begin{array}{c}\text { Ultrafil 3D } \\
\text { (G3) }\end{array}$ & $\begin{array}{c}\text { Fusionada } \\
\text { (G4) }\end{array}$ \\
\hline$p$ & 0,177 & 0,480 & 0,013 & 0,096 \\
\hline
\end{tabular}




\section{ANEXOS}




\section{CERTIFICADO DE CALIBRAÇÄO N. ${ }^{\circ} 1890 / 2003$}

Cliente: Dr. Fabio Strefezza

Endereço: Av. D. Pedro 1, $n^{\circ} 815$

Săo Paulo-SP - CEP -01552-001

\section{Identificaçăo do Material}

Material: Dispositivo para Medir Volume

$\mathrm{PI}-\mathrm{N}:{ }^{\circ}$ Ordem : $1191-2047 / 03 \quad$ Escala Graduada : 0-0,02 $\mathrm{ml}-20 \mu \mathrm{l}$

Fabricante : FGG

Divisăo de Escala: $0,0002 \mathrm{ml}-0,2,1$

N. ${ }^{\circ}$ de Identif.: BU - 3650

\section{Condiçōes de Calibraçăo}

Prod. Utilizado : Agua Destilada Temperatura da Agua : $20,1^{\circ} \mathrm{C}$ Pressầo Baromètrica: $937 \mathrm{hPa}$ Massa Especifica da Água: 0.9983 Temperatura do Ar: $19,5^{\circ} \mathrm{C}$ Umidade Relativa do Ar : $60 \%$ Data da Calibraçâo: 10/07/2003 Fator de Correção: 1,002673

\section{Método de Calibração}

Calibraçăo por gravimetria, pesada por diferença, conforme Procedimento LAMEVOL - FGG - MP-PC-001 - Rev.02 - 11/2002, baseado na NBR 11588 (ABNT MB 3119).

\section{$\underline{\text { Rastreabilidade }}$}

Baianca BL-001 - Certif. N. B-5a1302 - KNVAAGEN (RBC) - Data da Calibr. Dez2002 - Val : Aga/2003 Ternometro TE-003 - Cacti. N- TO3:4/2502 - LABELO (RBC) - Data da Calibr. - Maio/2002 - Val ; Maio/2004 U Jermometro TE-005 - Carte, N. T0315/2502 - LABELO (RBC) - Data da Caibr. - Maior2002 - Val ; Maior2004 A7 Barómetro BR-001 - Certif N LAPRE 0161/2001 - N1METRO - Data da Caliber - Maior2001 - Val. Maia/2006

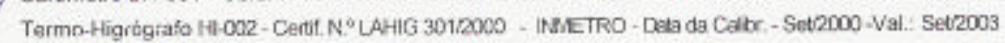

Densimevo DM-g03 - Certif. NN LAFLU 273/1999 - INMFTRO - Data da Calibr. - OuM1989 - Val: Out2003

É PROIBIDA A REPRODUÇĀO PARCIAL DESTE CERTIFICADO. ESTE CERTIFICADO SE RESTRINGE APENAS AO OBJETO CALIBRADO E NĀO SE ESTENDE A OUTROS DE MESMA ESPÉCIE.

RUA VISCONDE DE PAFNAIBA, 1520 - CEP 08164-300 - SAO PAULO - SP - TEL.: (11) 6693-7101 - FAX: (11) 6694-0343

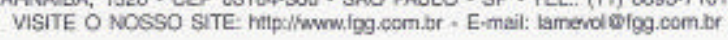


ANEXO A - Certificado de Calibração do sistema de mensuração de volume ( cont. )

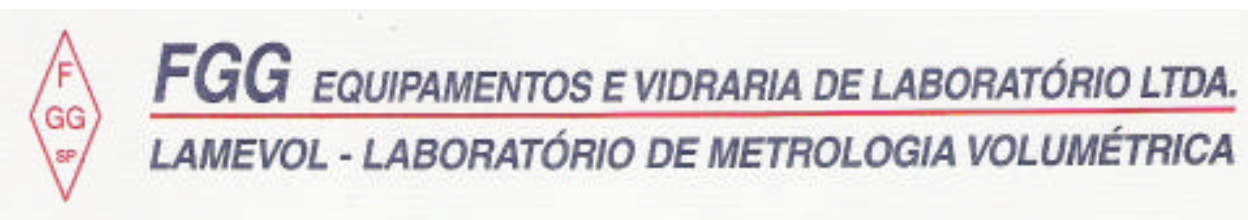

CONT. DO CERTIFICADO DE CALIBRAÇĀO N. ${ }^{\circ} 1890 / 2003$

Pag.: $2 / 2$

Resultados

Capacidade $a 20^{\circ} \mathrm{C}$

\begin{tabular}{|c|c|c|c|}
\hline $\begin{array}{c}\text { Leitura da Peça } \\
(\mathrm{ml})\end{array}$ & $\begin{array}{c}\text { Volume Corrigido } \\
(\mathrm{ml})\end{array}$ & $\begin{array}{c}\text { Incerteza Expandida } \\
\mathrm{U}(\mathrm{ml})\end{array}$ & $\begin{array}{c}\text { Fator de } \\
\text { Abrangencia K }\end{array}$ \\
\hline 0,002 & 0,0020 & $\pm 0,0003$ & 2,13 \\
\hline 0,004 & 0,0041 & $\pm 0,0003$ & 2,28 \\
\hline 0,006 & 0,0064 & $\pm 0,0002$ & 2,07 \\
\hline 0,008 & 0,0084 & $\pm 0,0002$ & 2,00 \\
\hline 0,010 & 0,0106 & $\pm 0,0002$ & 2,06 \\
\hline 0,012 & 0,0124 & $\pm 0,0007$ & 3,31 \\
\hline 0,014 & 0,0145 & $\pm 0,0007$ & 3,31 \\
\hline 0,016 & 0,0165 & $\pm 0,0012$ & 4,53 \\
\hline 0,018 & 0,0186 & $\pm 0,0012$ & 4,53 \\
\hline 0,020 & 0,0207 & $\pm 0,0014$ & 4,53 \\
\hline
\end{tabular}

A incerteza expandida relatada é baseada em uma incerteza padronizada combinada multiplicada por um fator de abrangência $k$, fornecendo um nivel de confiança de aproximadamente $95 \%$.

- O presente cerificado atende aos requisitos do ABNT - ISO/IEC - Guia 25:1993.

Săo Paulo, 11 de Julho de 2003
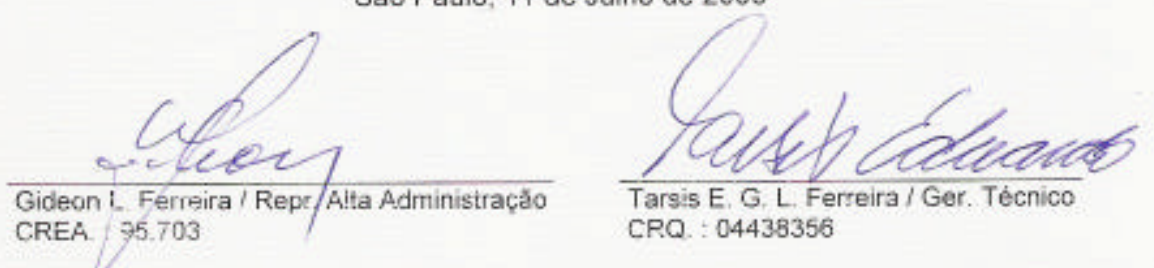

É PROIBIDA A REPRODUÇÃO PARCIAL. DESTE CERTIFICADO. ESTE CERTIFICADO SE RESTRINGE APENAS AO OBJETO CALIBRADO E NĀO SE ESTENDE A OUTROS DE MESMA ESPÉCIE.

FUA VISCONDE DE PAFNAIBA, 1580 - CEP 03164-300 - SñO PMLLO - SP - TEL.: (11) 6693-7101 - FAX (11) 6E94-0343 VISIE O NOSSO SITE: http:/Www.fgg,com.br - E-mail: lannewol \$lgg.com.br 